IZA DP No. 7139

Neighborhood Quality and Student Performance

Felix Weinhardt

January 2013 


\title{
Neighborhood Quality and Student Performance
}

\author{
Felix Weinhardt \\ London School of Economics (CEE, CEP, SERC) \\ and IZA
}

Discussion Paper No. 7139

January 2013

IZA
P.O. Box 7240
53072 Bonn
Germany

Phone: +49-228-3894-0

Fax: +49-228-3894-180

E-mail: iza@iza.org

Any opinions expressed here are those of the author(s) and not those of IZA. Research published in this series may include views on policy, but the institute itself takes no institutional policy positions. The IZA research network is committed to the IZA Guiding Principles of Research Integrity.

The Institute for the Study of Labor (IZA) in Bonn is a local and virtual international research center and a place of communication between science, politics and business. IZA is an independent nonprofit organization supported by Deutsche Post Foundation. The center is associated with the University of Bonn and offers a stimulating research environment through its international network, workshops and conferences, data service, project support, research visits and doctoral program. IZA engages in (i) original and internationally competitive research in all fields of labor economics, (ii) development of policy concepts, and (iii) dissemination of research results and concepts to the interested public.

IZA Discussion Papers often represent preliminary work and are circulated to encourage discussion. Citation of such a paper should account for its provisional character. A revised version may be available directly from the author. 


\section{ABSTRACT}

\section{Neighborhood Quality and Student Performance ${ }^{1}$}

Children who grow up in deprived neighborhoods underperform at school and later in life but whether there is a causal link remains contested. This study estimates the effect of very deprived neighborhoods, characterized by a high density of social housing, on the educational attainment of fourteen years old students in England. To identify the causal impact, this study exploits the timing of moving into these neighborhoods. I argue that the timing can be taken as exogenous because of long waiting lists for social housing in highdemand areas. Using this approach, I find no evidence for effects on student performance.

JEL Classification: J18, I21, J24

Keywords: neighborhood effects, housing policy

Corresponding author:

Felix Weinhardt

Centre for Economic Performance (CEP)

London School of Economics

Houghton Street

London, WC2A 2AE

United Kingdom

E-mail: f.j.weinhardt@Ise.ac.uk

\footnotetext{
${ }^{1}$ ESRC funding gratefully acknowledged (Ref: ES/F022166/1, ES/J003867/1). Helpful comments from Sascha Becker, Thomas Breda, Christian Hilber, Ifty Hussain, Victor Lavy, Tim Leunig, Alan Manning, Richard Murphy, Henry Overman, Frédéric Robert-Nicoud, Stephen Ross, Olmo Silva, Petra Todd, and Yves Zenou, and participants of the EALE/SOLE conference in London, the NARSC Urban Economics Association Conference in San Francisco, the Spatial Econometrics Conference in Barcelona, the LSE-SERC Urban Economics Seminar, the LSE-CEP Labour Market Workshop, the 2010 IZA Summer School, the 2010 ZEW Workshop on "Evaluation of Policies Fighting Social Exclusion"; and the CEP-CEE Education Workshop are gratefully acknowledged. Previous working paper version: Weinhardt (2010). I declare that I have no relevant or material financial interest that relate to the research described in this paper. All remaining errors are my own.
} 


\section{I.Introduction}

Children who grow up in deprived neighborhoods underperform at school and later in life. In England, the most deprived neighborhoodshave high concentrations of social housing (public housing)and are characterized by very high unemployment and extremely low qualification rates, high building density, over-crowding and low house prices.Growing up in social housing is associated with unfavorable outcomes:adults who lived in social housing during their childhood are more likely to be depressed, unemployed, cigarette smokers, obese, and have lower qualification levels compared to peers in their cohort who never lived in social housing (Lupton et al. 2009). The following concern arises: if living in a bad neighborhood has direct negative effects on outcomes such as school results, this could in extreme cases constitute a locking-in of the disadvantaged into a spatial poverty trap: 'once you get into a bad neighborhood, you and your children

won't get out ${ }^{2}$. In a society that believes that everyone deserves a fair chance, it is hence not surprising that this disadvantageassociated to deprived neighborhoods has attracted attention from researchers and policymakers alike ${ }^{3}$.

This paper establishes whether moving into localized high-density social housing neighborhoods causes a deterioration in the school attainment of fourteen-year-old students. The English setting offers a unique opportunity to answer this research question for two reasons.

Firstly, the geographical sorting problem needs to be overcome, which otherwise induces spurious correlations between individual and neighbors' outcomes (Manski, 1993, Moffitt 2001). In order to identify the causal impact of neighborhood deprivation on student attainment this study exploits the timing of moving into these neighborhoods around the national age-fourteen Key Stage 3 (KS3) exam. In England, the timing of a move can be taken as exogenous because of long waiting lists for social housing in highdemand areas. In these areas, waiting times can exceed ten years, and I argue that we can

\footnotetext{
${ }^{2}$ This might be the case because of peer group and role model effects (Akerlof 1997; Glaeser and Scheinkman 2001), social networks (Granovetter 1995; Calvó-Armengol and Jackson 2004; Baver et al. 2008; Zenou 2008; Small 2009; Figlio et al. 2011), conformism (Bernheim 1994; Fehr and Falk 2002) or local resources such as school quality or other environmental (Durlauf 1996, Lupton 2005). It is not the aim of this paper to distinguish between these theoretical channels.

${ }^{3}$ Housing policies that rest on the idea of a causal channel from the place of residence to individual outcomes are inclusionary zoning and desegregation policies, as well as regeneration and mixed-housing projects, such as 'Hope VI' in the US, or the 'mixed communities' initiative in England (e.g. Cheshire et al. 2008).
} 


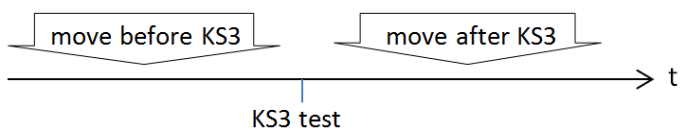

FIGURE 1: KS3 DISCONTINUITY

therefore compare test scores of students who experience large deteriorations in neighborhood quality before the exam, to test scores of other pupils who will be subjected to the same neighborhood treatment in the future (Figure 1). Naturally, a student's result in the KS3 exam can only be influenced by the low quality of her new neighborhood if she moves into this neighborhood before taking the test. Later movers only receive a (future) 'placebo' treatment and serve as natural control group as they are likely to share many unobserved characteristics common to social tenants ${ }^{4}$. We know that pupils from deprived family backgrounds are prioritized, but identification only relies on them being prioritized in a similar way before and after the KS3 test. This means that we can relax the usual assumption that social housing neighborhood allocation is quasirandom as such (e.g. Oreopoulos 2003). Time-invariant preferences or unobserved institutional arrangements that could give rise to neighborhood sorting can be captured by the neighborhood fixed effect. The remaining assumption required for identification is that allocation and individual sorting preferences for particular neighborhoods do not change over the study period. In support of this assumption, I show that a rich set of individual characteristics fails to predict the time of the move. I interpret this as direct evidence in favor of the validity of the identification assumption of quasi-random timing.

Secondly, nation-wide census data makes it possible to track individual residential mobility for two cohorts of students in England; the study is therefore not limited to a small number of neighborhoods or of cities. The richness of the data also allows including controls for a potential direct effect of moving, earlier attainment, family background and school quality.

The main finding of this study is that early movers into deprived social housing neighborhoods experience no negative effects on their school attainment relative to late movers. While it is demonstrated that there are large negative associations between moving into deprived areas and school outcomes, these negative correlations cease to

\footnotetext{
${ }^{4}$ This strategy is related to Rothstein (2010) who studies effects of teacher quality and exploits the fact that future teachers cannot affect contemporaneous value added test scores.
} 
exist once controlling for group-specific observable and unobservable characteristics in a difference-in-difference framework.

To the best of the author's knowledge, exploiting the timing of moving when waiting lists are long is a novel strategy to study neighborhood effects. 5 Besides this methodological innovation, the finding of no effects on school outcomes from moving into high-density social housing projects informs the literature. For educational outcomes, the only existing experimental study, the Moving to Opportunity (MTO) intervention, a mobility voucher scheme, finds little evidence for neighborhood effects in both the short and the long-run (Katz et al. 2001, Sanbonmatsuet al. 2006, Kling et al. 2007, Ludwig et al. 2012). However, the MTO has been questioned by some because of its focus on relatively small neighborhood-level changes (i.e. small 'treatments') and limited geographical representativeness (Quigley and Raphael 2008, Clampet-Lunquist and Massey 2008, Small and Feldman 2012). Furthermore, the non-experimental literature tends to find evidence in favor of neighborhood effects on educational outcomes, which is the opposite of the MTO. Goux and Maurin (2007) study the effect of close neighbors in France and find strong effects on end of junior high-school performance and Card and Rothstein (2007) find effects of city-level racial segregation on the black-white test score gap ${ }^{6}$.To the author's knowledge, this is the first non-experimental study that does not find evidence for short-term effects on school outcomes from highly deprived neighborhoods, thus supporting the conclusions from the experimental literature.

The rest of the paper is structured as follows: The next section describes the empirical strategy, section III the institutional setting and the data; Section IV discusses the results; and Section V presents a battery of robustness checks before I conclude.

Existing research used instrumental variables (Cutler and Glaeser 1997, Goux and Maurin 2007); aggregation (Card and Rothstein 2007); institutional settings (Oreopoulos 2003, Jacob 2004, Gould et al. 2004, Gurmuet al. 2007, Goux and Maurin 2007); fixed effects (Aaronson 1998, Bayer et al. 2009, Gibbons et al. 2011) or experimental setups (Katz et al. 2001, 2007, Sanbonmatsuet al. 2006, Ludwig et al. 2012).

${ }^{6}$ In another paper Jacob (2004) does not find effects of public housing demolitions on student achievement, but in his setting students move between very similar neighborhoods so he is not testing for neighborhood effects but an independent effect of public housing. In addition, there is a related literature that shows that peers matter in school (i.e. Sacerdote 2001, Carrell et al. 2009, Lavy et al. 2012), and that neighborhoods matter for labor market outcomes (Cuter and Glaeser 1997, Ross 1998, Ananat 2007, Weinberg 2000, 2004, Bayer et al. 2008), although again the MTO and Oreopoulos (2003) do not find evidence for neighborhood effects on labor market outcomes. For a full review of the related literature see Ross (2011). 


\section{II.Empirical strategy}

This study focusses on identifying the effect on educational attainment of moving into high-density social housing neighborhoods. We know that people sort into their neighborhoods along socio-demographic characteristics, which could induce spurious correlations between neighborhood characteristics and pupil outcomes if unobserved (Manski 1993, Moffitt 2001). Any study that makes causal claims about the relationship between neighborhood characteristics and individual outcomes needs to present a strategy to overcome this sorting problem. The focus of this study is on pupils who move into social housing neighborhoods, the worry is hence that these pupils carry unobserved characteristics that explain their educational underperformance and are also linked with the fact that their parents got admitted into social housing in the first place. These factors would generate spurious correlations between neighborhood characteristics and individual outcomes even in the absence of any neighborhood effects.

As a novel strategy, this study exploits the timing of the move to control for all observed and unobserved factors that are common to pupils moving into high density social housing neighborhoods. Figure 2 illustrates this identification strategy. The time when the Key Stage 3 (KS3) exam, a national and externally marked test, is taken is denoted by $t$. The time for the national and externally marked Key Stage 2 (KS2) exam by $t-1 . t-1$ to $t$ span the English academic years seven to nine. This is equivalent to $6^{\text {th }}$ to $8^{\text {th }}$ grade in the US context, more details on institutional background are given in section III. Conversely, $t$ and $t+1$ cover the academic years ten and eleven after the KS3 $\left(9^{\text {th }}\right.$ and $10^{\text {th }}$ grade in the US). We can now compare test score value added of pupils who move into deprived social housing neighborhoods before taking the KS3 test, in the period from $t-1$ to $t$, to pupils who also move into deprived social housing neighborhoods, but after sitting the KS3 exam in the period between $t$ and $t+1$. The latter group only received a 'placebo' treatment as the future neighborhood cannot affect test scores of the test taken at time $t$ and thus serves as control group. This group is likely to share many-potentially unobserved- characteristics common to all pupils who move into high-density social housing neighborhoods. ${ }^{7}$

\footnotetext{
${ }^{7}$ A further problem in neighborhoods effects research is the "reflection problem". This issue arises because individuals might not only be affected by other individuals in their neighborhood but might equally affect these themselves (Manski 1993). If neighborhood effects exit, this causes a reverse causality problem that upward biases the
} 


\section{A. The production function of educational attainment in the neighborhood}

Formally, assume that test scores can be modeled as a linear function of neighborhood, school and individual characteristics in the following way:

$$
y_{i g n s c t}=\mathbf{Z}_{n t}{ }^{\prime} \beta+\mathbf{x}^{\prime}{ }_{i t} \boldsymbol{\gamma}+\mathbf{x}^{\prime}{ }_{i t} \boldsymbol{\delta} t+\mathbf{S}^{\prime} \boldsymbol{\varphi}+\mathbf{S}^{\prime} t \kappa+c_{c}+c_{c} t+\varepsilon_{i g n s c t}
$$

where $y_{\text {ignst }}$ denotes test scores of individual $i$ of group $g$, in neighborhood $n$, school $s$, cohort $c$ in year $t . \mathbf{Z}_{n t}$ denotes time-varying neighborhood characteristics that could influence attainment at school, like the absence of role models, etc. The vector $\mathbf{x}$ denotes individual-level characteristics that affect test scores, like family background characteristics or earlier test scores. I further allow these characteristics to have a timevarying effect on test outcomes, denoted by $\mathbf{x}_{i t}^{\prime} \boldsymbol{\delta} t$. The matrix $\mathbf{S}$ denotes school-level characteristics and $c$ allows for different intercepts for the different cohorts, and both could have effects depending on the timing, as well.

Further, let us assume that the error term contains the following elements:

$$
\varepsilon_{\text {ignsct }}=\alpha_{i}+z_{n}+z_{n} t+s_{s}+s_{s} t+\phi_{g}+\phi_{g} t+e_{i g n s c t}
$$

Where $\alpha_{i}$ represents unobserved individual effects such as motivation, $z_{n}$ unobserved neighborhood characteristics, $s_{s}$ unobserved year school quality and $\phi_{g}$ unobserved characteristics of belonging to group $g$. I think of $g$ as representing time-invariant characteristics which are common to pupils who move into social housing neighborhoods. I further allow the unobserved neighborhood, school and group characteristics to have time-varying effects through $z_{n} t, s_{s} t$ and $\phi_{g} t$. Lastly, $e_{i g n s c t}$ is the error term which we assume to be random. The problem is that all former components might correlate with individual and neighborhood specific variables from equation (1) for the discussed reasons and hence bias any estimates.

The first step to potentially overcome these problems is to difference the equation:

$$
\left(y_{\text {ignsct }}-y_{\text {ignsct }-1}\right)=\left(\mathbf{Z}_{n t}-\mathbf{Z}_{n t-1}\right)^{\prime} \beta+\mathbf{x}_{i}{ }^{\prime} \delta+\mathbf{S}^{\prime} \kappa+c_{c}+\left(\varepsilon_{\text {ignsct }}-\varepsilon_{\text {ignsct }-1}\right)
$$


Where $\left(y_{\text {ignsct }}-y_{\text {ignsct }-1}\right)$ is the test-score value added between KS2 and KS3 modeled as a function of changes in the neighborhood environment $\left(\mathbf{Z}_{n t}-\mathbf{Z}_{n t-1}\right)$, individual characteristics $\mathbf{x}_{i}$ and school-characteristics $\mathbf{S}$ that affect value-added. Note that the timeindependent effects of individual characteristics, belonging to a particular cohort and of the matrix of school variables all cancel out.

The differenced error term now has the following components:

$$
\left(\varepsilon_{\text {ignsct }}-\varepsilon_{\text {ignsct }-1}\right)=z_{n}+\phi_{g}+s_{s}+v_{\text {ignsct }}
$$

All time-invariant unobserved characteristics of equation (1.2) that do not have a timevarying effect cancel out. What is left are the unobserved neighborhood characteristics that could affect value added $z_{n}$, the group effects that have a time-varying effect $\phi$, unobserved school-level variables that affect value-added $s_{s}$ and $v_{\text {ignsct }}$, which I assume to be random. Note that I will cluster the error term at the neighborhood-level to allow for local correlations in the error term matrix. Compared to (1.2), this differenced error term does not contain any unobserved characteristics that affect test score levels. In some of my regressions I can include fixed effects to control for two of the remaining three nonrandom unobserved components $z_{g}$, and $s_{s}$.

From an identification point of view this model is preferable to the levels-model presented earlier. This is because all unobserved constant factors, in particular family background or individual motivation, are now controlled for and can therefore not generate spurious correlations through the sorting mechanism. Furthermore, by including fixed effects for neighborhoods and schools any unobserved constant local factors affecting value-added can be taken care of. This means that any constant unobserved neighborhood or school characteristics can be captured and hence cannot induce spurious correlations between neighborhood quality changes and test score progress. However, a remaining worry is that pupils who move into social housing share individual or background characteristics that are unobserved and correlate with neighborhood changes. These unobserved group characteristics are captured by $\phi_{g}$ in equation (2.2) and cannot be directly controlled for. As I outlined in the beginning of this section, my 
strategy addresses this final concern by comparing early movers to late movers ${ }^{8}$, so pupils who experienced a neighborhood level treatment before sitting the KS3 exam at time $t$ to pupils who moved later and hence only received a 'placebo' treatment as future neighborhood changes cannot affect past value added.

In order to mirror the setup from Figure 2 and to compare pupils who moved before taking the test to the placebo group of pupils who moved into high-density social housing neighborhoods only after sitting the KS3 test at time $t$ in a regression framework, we need to define indicator variables for moving into a high-density social housing neighborhood:

$D(S H)_{i, t,-1}\left\{\begin{array}{l}=1 \text { if pupil moves into social housing between } t \text { and } t-1 \\ =0 \text { otherwise }\end{array}\right.$

$D(S H)_{i, t, t+1}\left\{\begin{array}{l}=1 \text { if pupil moves into social housing between } t \text { and } t+1 \\ =0 \text { otherwise }\end{array}\right.$

$D(S H)_{i, t-1, t+1}\left\{\begin{array}{l}=1 \text { if pupil moves into social housing between } t-1 \text { and } t+1 \\ =0 \text { otherwise }\end{array}\right.$

I use these indicator variables to proxy for neighborhood quality changes $\left(\mathbf{Z}_{n t}-\mathbf{Z}_{n t-1}\right)$, as a catch-all proxy for the large deteriorations in neighborhood quality these pupils experience (discussed in detail in sectionIII C).

One concern is that a move might also directly affect value added, and not only indirectly through the change in neighborhood quality. The 'placebo' group only moves after taking the test so that the neighborhood quality change cannot affect test scores, but equally they don't move before taking the test. If there was a direct effect of mobility on test scores, i.e. through disruption, this could bias the estimates. To allay these concerns I will difference out the pure effect of moving using the population of pupils who move but not into social housing. To do this, let's define the following sets:

$D(M)_{i, t, t-1} \begin{cases}=1 & \text { if pupil moves between } t \text { and } t-1 \\ = & 0 \text { otherwise }\end{cases}$

${ }^{8}$ I follow the literature (i.e. Katz et al. 2001, Jacob 2004) and rely on pupils who move to generate variation in the neighborhood variables $\left(z_{n t}-z_{n t-1}\right)$, since neighborhoods change very slowly over time. 
$D(M)_{i, t, t+1} \begin{cases}=1 & \text { if pupil moves between } t \text { and } t+1 \\ =0 & \text { otherwise }\end{cases}$

$D(M)_{i, t-1, t+1}\left\{\begin{array}{l}=1 \text { if pupil moves between } t-1 \text { and } t+1 \\ =0 \text { otherwise }\end{array}\right.$

Finally, in the value-added model (2.1) we assume that past test scores predict today's test scores with an coefficient of one. I relax this assumption and instead of differencing test scores manually on the left-hand-side include past test-scores as control variable on the right-hand side of the equation. There is a worry that the coefficient on the past test score will be downward biased if the KS2 test only measures ability with an error (see Todd and Wolpin 2003). In this application however the way we control for past test scores - or if we control for past test scores at all- makes little difference to the estimates. This is because the placebo group is extremely similar to the treatment group, which I come back to in section $\mathrm{V}$.

With these ingredients we can now construct a difference-in-difference estimate from equations (2.1) and (2.2) using the indicator variables defined above. To see this, let us first set up a model for pupils who moved into high-density social housing neighborhoods between time $t-1$ and $t$. Substituting the indicator variables for the neighborhood-changes and (2.1) directly into the equation we get:

$$
y_{i g n s c t}=\gamma_{1} D(S H)_{i, t-1, t}+\gamma_{3} D(M)_{i, t-1, t}+\theta y_{i g n s c t-1}+\mathbf{x}_{i}{ }^{\prime} \delta+\mathbf{S}^{\prime} \kappa+c_{c}+z_{n}+\phi_{g}+s_{s}+v_{i g n s c t}
$$

Here, test scores in time $t$ are modeled as a function of moving into a high-density social housing neighborhood before the test controlling for moving before the test. Further controls are previous test national test scores, individual and school characteristics, and a cohort-dummy. Potentially unobserved remain neighborhood specific effects $z_{n}$, group characteristics $\phi_{g}$ and the school unobservables that affect KS3 conditional on KS2. Note that we can write down a similar model for pupils who moved into high-density social housing neighborhoods after sitting the KS3 test between time $t$ and $t+1$ :

$$
y_{i g n s c t}=\gamma_{1} D(S H)_{i, t, t+1}+\gamma_{3} D(M)_{i, t, t+1}+\theta y_{i g n s t-1}+\mathbf{x}_{i}{ }^{\prime} \delta+\mathbf{S}^{\prime} \kappa+c_{c}+z_{n}+\phi_{g}+s_{s}+v_{i g n s c t}
$$


The only difference is that (3.2) now estimates the placebo-effect of moving into highdensity social housing neighborhoods between $t$ and $t+1$ on test scores taken at time $t$. We can now combine (3.2) and (3.1) into a single equation:

$$
\begin{aligned}
y_{i g n s c t}= & \gamma_{1} D(S H)_{i, t-1, t}+\gamma_{2} D(S H)_{i, t-1, t+1}+\gamma_{3} D(M)_{i, t-1, t}+\gamma_{4} D(M)_{i, t-1, t+1} \\
& +\theta y_{i g n s c t-1}+\mathbf{x}_{i}^{\prime} \delta+\mathbf{S}^{\prime} \kappa+c_{c}+z_{n}+s_{s}+v_{i g n s c t}
\end{aligned}
$$

This equation estimates the effect of moving into a high-density social housing neighborhood on KS3 test scores at age $14 \gamma_{1}$, controlling against characteristics of the placebo group of pupils who moved after the test captured by $\gamma_{2}$. Potential direct effects of moving are absorbed by the general moving dummies and $\gamma_{3}$ and $\gamma_{4}$. Since there might be further differences between pupils moving before $t$ and after $t$, I include previous test scores $y_{i g n s t-1}$, individual characteristics $\mathbf{x}_{i}$, school characteristics $\mathbf{S}$ and a cohort dummy $c_{c}$. As I discuss in section $\mathrm{V}$ these observable differences turn out to be unimportant. A remaining worry is that -unobserved to the researcher-, early movers might move to systematically different neighborhoods. To control for this I can include neighborhoodfixed effects $z_{n}$ in some of my specifications. Similarly, school fixed effects $s_{s}$ can be included to control for any unobserved school quality differences between early (the treatment group) and late (placebo/control group) movers.

Importantly, the unobserved constant characteristics for pupils moving into social housing neighborhoods $\phi_{g}$ drop out, as this term is now perfectly collinear with

$D(S H)_{i, t-1, t+1}$. This means that test score improvements of pupils who move into highdensity social housing neighborhoods are now directly compared to improvements of other pupils who move into high-density social housing neighborhoods. Any constant unobserved group characteristics that correlated with test scores and family background, for example, are therefore taken care of. This is the main advantage of the difference-indifference setup.

\section{B. Required assumptions for identification}

Before turning attention to potential threats to identification, I first discuss the assumptions that need to hold for identification in more detail. In potential outcomes the setting can be represented as follows: 


$$
\begin{aligned}
& \mathrm{E}\left\{y_{i g n s c t} \mid D(S H)_{i, t-1, t}=1\right\}-\mathrm{E}\left\{y_{i g n s c t} \mid D(S H)_{i, t-1, t}=0\right\} \\
& =\mathrm{E}\left\{y_{i g n s c t}^{1}-y_{i g n s c t}^{0} \mid D(S H)_{i, t-1, t}=1\right\} \\
& +\left[\mathrm{E}\left\{y_{i g n s c t}^{0} \mid D(S H)_{i, t-1, t}=1\right\}-\mathrm{E}\left\{y_{\text {ignsct }}^{0} \mid D(S H)_{i, t-1, t}=0\right\}\right]
\end{aligned}
$$

The first line defines the difference in the expectation of test score results for the same individual $\mathrm{i}$ who either moves into social housing between $t-1$ and $t$, denoted by $D(S H)_{i, t-1, t}=1$, or does not, i.e. conditional on $D(S H)_{i, t-1, t}=0$. Of course, both of these outcomes can never be observed simultaneously for the same individual. These terms can be rearranged into an effect of Treatment on the Treated (ToT) and Selection Bias. $y_{i g n s c t}^{1}$ and $y^{0}{ }_{i g n s c t}$ denote the two potential outcomes for individual $i$. Here, the term in the second row represents the ToT, and the term in the square brackets sorting into treatment, which is the selection bias. The concern is that this expression does not equal zero. This term represents the difference between test scores of pupils who do not move into social housing, compared to the counterfactual of what pupils who move into a social housing neighborhood would have obtained, had they not moved. This term is probably not equal zero because pupils who move into social housing have parents who are eligible for social housing, and thus have lower incomes and further characteristics that are likely to correlate to a pupil's test score at school. To overcome this problem, this study makes the following assumption:

$$
\left\{y_{\text {ignsct }}^{1}, y_{i g n s c t}^{0}\right\} \perp\left\{D(S H)_{i, t-1, t} \mid D(S H)_{i, t-1, t+1}=1\right\}
$$

This expression states that the timing of a move, i.e. moving before the test denoted by $D(S H)_{i, t-1, t}$ is independent of individual characteristics conditional on moving into a social housing neighborhood in a high demand area at some point, denoted by $D(S H)_{i, t-1, t+1}=1$. This means that conditional on moving into social housing at some point, the timing of the move is not related to observable and unobservable characteristics and this variation can be used for estimation. If this holds, we get:

$$
\begin{aligned}
& \mathrm{E}\left\{y_{i g n s c t} \mid D(S H)_{i, t-1, t}=1\right\}-\mathrm{E}\left\{y_{i g n s c t} \mid D(S H)_{i, t-1, t}=0\right\} \\
& =\mathrm{E}\left\{y_{\text {ignsct }}^{1}-y^{0}{ }_{i g n s c t} \mid D(S H)_{i, t-1, t+1}=1\right\}
\end{aligned}
$$

The selection term disappears since it equals zero conditional on $D(S H)_{i, t-1, t+1}=1$. This is because there are assumed to be no differences between early and late movers 
conditional on moving at some point. Therefore the observed difference in test scores between early and late movers into social housing can be interpreted as the treatment-onthe treated-effect, as long as the independence assumption in equation (6) holds.

The key advantage of the difference in difference framework is that constant factors $\phi_{g}$ that correlate with moving into high-density social housing neighborhoods and test scores are absorbed. This is important because we might be worried about sorting of certain types of families to neighborhoods based on unobserved characteristics. In the DiD framework any institutional factors such as discrimination against certain types of applicants, 'pushy parents' or sorting that is constant over time do not cause bias. Intuitively, if a social planner always offers places in nicer neighborhoods to families with certain characteristics for example, this is going to happen equally before and after the KS3 test. Equally, as long as the number of 'pushy parents' does not change much over time, this will not affect the estimate. Furthermore, in some specification I can include neighborhood destination fixed effects. In these specifications we are effectively comparing the value added in test scores of pupils who moved into the same neighborhood, but one group moving before taking the test at time $t$, while the other group moved just afterwards. Any remaining constant unobservable characteristic that is related to individual neighborhood quality will be captured by the fixed effect. As we will see, even including neighborhood destination fixed effects will not change the results.

If these factors remain unchanged over the study period, they cannot be correlated to the timing conditional on moving at some point, just as spelled out by equation (6). Therefore, $\gamma_{1}$ in specification (4) would still uncover the effect of the treatment on the treated. Note that this is a relaxation of the assumption that discrimination or institutional preferences for certain types of families do not exist at all, and that families are fairly randomly allocated (as in Oreopoulos 2003). Here it is only required that these factors do not change over the time of the study period.

\section{Social housing waiting times and potential threats to identification}

As a results of focusing on pupils who move into social housing neighborhoods at different times the hope is to single out variation in neighborhood quality that is exogenous, i.e. independent of prior characteristics. The main threat to identification is that early and late movers into high-density social housing neighborhoods are not comparable. This could occur for a number of reasons. 


\section{Parental shocks and eligibility for social housing}

Since allocation of social housing is needs based, we are worried that unobserved negative shocks that made the family eligible for the social housing sector might also affect test scores negatively ${ }^{9}$. To address this concern, the DiD strategy exploits the fact that people who apply for social housing in England are not directly allocated a place but usually have to remain on waiting lists for years. The idea is that if people have been on the waiting list for social housing for many years, current changes in characteristics cannot be correlated to the timing of the neighborhood they eventually move into. Unfortunately no individual-level data on actual waiting times is available, which would allow us to ensure that waiting times are long directly. Anecdotal evidence suggests that waiting times easily extend to periods of seven to fourteen years ${ }^{10}$. Fortunately, waitinglist related information is available by local authority. To ensure waiting times are sufficiently long, I only include in the analysis local authorities in which at least five per cent of the population have been on a waiting list in the year 2007. ${ }^{11}$ The share of the population on a waiting list is certainly not a perfect proxy for waiting times but should be highly correlated. The hope is that this ensures that families who get into social housing at different points in time are very similar in their average characteristics. That is, the timing of the move, but neither the decision to move itself nor the wish to get into social housing, should be exogenous in high demand areas, so that assumption (6) holds. In these areas, pupils with parents who apply to social housing at different times should share similar observable and unobservable characteristics but have different 'exposure' times to a social housing neighborhood, as generated through the precise timing of when they are offered a place.

It is of course impossible to show that early and late movers are quasi-identical. To allay some of these concerns, in specification (4) I can include an array of additional control variables such as ethnicity, free school meal status, gender and previous test scores. For identification it is now required that pupils who move into high-density social housing neighborhoods are comparable in unobservables conditional on these observable

${ }^{9} \mathrm{~F}$

For a detailed account of the social housing sector in England see Online Appendix A1

${ }^{10}$ The London Borough of Newham publishes general waiting times by housing stock: http://webcache.googleusercontent.com/search?q=cache:bxpvuuEw4WIJ:www.newham.gov.uk/Housing/HousingOp tionsAndAdvice/ApplyingForCouncilHousingOrHousingAssociationProperty/AverageWaitingTimesforAllocatedHous ing.htm + social + hosuing + waiting + times + uk\&cd $=5 \& \mathrm{hl}=$ en\&ct $=\mathrm{clnk} \& \mathrm{gl}=\mathrm{uk}$

11 There is very little variation over time in this indicator. 
characteristics. It will turn out that including these controls does not affect any conclusions since early and late movers are very similar in observable characteristics.

Since I cannot show directly that the waiting times are sufficiently long, the skeptical reader might still believe that a negative shock made a family eligible for social housing in some areas may affect the test scores of early and later movers differently. However, note that in the standard additive test score production function these shocks would already be captured by the end of primary school KS2 test scores $y_{\text {ignsct-1 }}$ at least for the early movers. In section V I return to this issue and show that early and late movers look statistically identical in their observable characteristics, in particular in previous test scores, which I believe lends strong support to the identification assumption that late movers are a suitable control group for early movers into high-density social housing neighborhoods.

\section{Supply of social housing ${ }^{12}$}

Rather than from the parental side, if criteria for admissions into social housing changed over the study period this could invalidate late movers as control group for early movers and thereby violate the common trends assumption. Fortunately, the centrally defined eligibility criteria stayed unchanged over the study period, which should ensure that the demand side has been relatively stable. Similarly, the supply side has been very consistent. The size of the sector has expanded very slowly and steadily over the study period. Net additions to the social sector have averaged around 160,000 dwellings throughout the 1990s, so even a decade before the period of interest, and early 2000s (Hills 2007, p. 30). Taken together this should imply that we can roughly view the social housing sector in steady state equilibrium over the study period in the 2000 s.

\section{Direct effects of moving into social housing ${ }^{13}$}

A further issue is that parents might save on rent when they move into social housing. As it turns out this is unlikely to be the case in the English setting since parents eligible for social housing are likely to be eligible for housing benefits. Importantly, housing benefits are responsive to residential changes or changes in rent; hence families who get offered a place and move into social housing where rents are fifty to sixty per cent lower

\footnotetext{
${ }^{12}$ For a detailed account of the social housing sector in England see Online Appendix A1.

${ }^{13}$ For a more detailed account of housing benefits see Online Appendix A2
} 
than in the private rented sector will face an immediate and simultaneous reduction in housing benefits. This institutional setting gives rise to a unique situation where we do not expect any direct income effects from moving into social housing.

Furthermore, I can include free school meal status, a time-varying control for parental income, as a control variable in specification (4). Again, the inclusion of the additional control variable will make no difference to the interpretation of the results. Furthermore, in section V I show that early and late movers are identical even with respect to their time-varying free school meal eligibility. Therefore it is unlikely that any income effects confound interpretation of the results.

\section{The English school system, data and descriptive statistics}

\section{A. The English school system}

The English school system is organized into four key stages, in which learning progress is assessed at the national level. Of interest for this study is the Key-Stage 2 (KS2) assessment at the end of primary/junior school, and the Key-Stage 3 (KS3) assessment, which assesses pupils' progress in the first three years of compulsory secondary education (figure 2). The KS2 assessment is at the age of 10/11, while the KS3 is carried out at the age of 13/14. I use the average performance across the three core subjects, English, Mathematics and Science, to measure attainment. Since I compute cohort-specific per centiles of the respective KS2 and KS3 scores, individual results between the two tests and cohorts are directly comparable. The KS3 score is of no direct importance to parents or housing organizations and is not a high-stakes test in a sense that anyone would specifically avoid moving before the test or time a move around it. On the other hand, it correlates highly with later school and labor market outcomes and is therefore of general policy interest.

It is important to notice that access to secondary schools in non-selective. As a result, and in contrast to many other countries, there is no exact mapping between neighborhoods and schools. Indeed, five pupil who live in the same postcode on average attend two to three different secondary schools, and every secondary school has pupils from about sixty neighborhoods. This feature of the English school system will allow to control for school fixed effects without losing the neighborhood-level variation (similar as in Gibbons et al. 2011). 


\section{B. The Pupil Level Annual School Census}

The Department for Education (DfE) has collected pupil-level census information from all state schools in England since 1996. From the 2001/02 cohort onwards, detailed pupil-level information such as ethnic background, free school meals eligibility (FSME), and pupils' postcode of residence is collected in the pupil-level annual school census (PLASC). People eligible for FSME are likely to receive Income Benefits, Job-seekers' Allowance and to be single parents with a dependent child (Hobbs et al. 2007). This variable serves as proxy for the lowest income groups. Overall, given the extent of the census data, I can construct a pupil-level panel of two cohorts for five consecutive years and track individual pupils from their first (academic year seven) to fifth year (academic year eleven) in secondary education. For the first cohort this corresponds to the period from 2001/02 to 2005/06, and for the second from 2002/03 to 2006/07.

The PLASC is collected in the middle of each January, close to when the Key Stage 3 tests are taken in May. I ignore this time mismatch of four months here, but address it directly in one of the robustness checks. I can use the residential information at the Census 2001 Output Area (OA) level to identify all pupils who have moved during the academic years eight to eleven on a yearly basis. OAs were originally constructed to include a comparable number of households: each contains about four to five postcodes and on average 125 households. I use the OA to define what I understand as a 'neighborhood'.

Unfortunately, the PLASC does not contain any information on housing tenure. Hence the next and crucial step is to identify who lives in a social housing neighborhood and who does not. I do this using neighborhood information from the 2001 Census of Population. The 2001 Census of Population is the most recent available decennial survey of all people and households living in England and Wales. A wide range of socioeconomic variables was collected and made available at various levels of spatial aggregation. This census was collected one year before my analysis starts and I extract pre-treatment neighborhood-level information on the total number of households that rent from the council (local authority) or a registered social landlord or housing association, the male unemployment rate, the level of education, the level of car ownership, building density, overcrowding, average number of rooms per household and the percentage of lone parents with dependent children. The first two variables are used to calculate the percentage of households living in social housing for each OA. There has 
been very little change in the stock of social housing since 2001, and mobility is limited, as discussed in section II.C. As a result, it is unlikely that these neighborhoods have changed dramatically since the 2001 Census (Hills 2007, pp. 169ff). Therefore I can use that census to identify high-density social housing neighborhoods for the entire study period. Notice that even if annual information was available I would prefer to use the pre-dated 2001 Census information because later changes in neighborhood quality could be endogenous to variation that I am using for estimation.

Following our identification strategy, the timing of movers into one-hundred-per cent social housing neighborhoods must be exogenous, whereas movers into zero-per cent social housing neighborhoods, at the other extreme, are never constrained by social housing waiting lists. However, only very few OAs are completely social housing. This is why I am forced to use a lower threshold of eighty per cent. If eighty per cent of all households in a particular OA live in social housing, then it is still very likely that a pupil who lives in that $\mathrm{OA}$ also lives in social housing. Therefore, everyone living in an OA with eighty per cent or more households being in social housing is treated as living in a social housing neighborhood, and all others are not. Using this threshold, by tracking OA changes over the years it is now possible to identify those who move out of an area with less than eighty per cent of social tenants into an area with eighty per cent or more. As I already know, mobility within the social housing sector is close to zero. Hence to identify pupils who move into social housing I focus the analysis on those who move into an OA with more than eighty per cent of households in social housing and stay there. From now on this will be referred to as 'moving into a social housing neighborhood'.

Finally, the analysis is restricted to comprehensive, grammar, secondary modern and technical schools that span the whole period between KS2 and two years after the KS3. Other less common school types such as middle schools are not organized around the Key Stages the same way and often require school changes after year nine, which could confound any analysis that focuses on moves between years seven and eleven. The schools included cover ninety per cent of pupils in English state education. ${ }^{14}$

In my final dataset, 2,094 pupils move into such social housing neighborhoods between their seventh and eleventh academic year. 703 pupils move into social housing from year

\footnotetext{
14 Note also that there is a small fraction of pupils who move more than once during the study period. These students are not representative of 'stayers' and are not included in the main analysis.
} 
seven to eight, 516 from year eight to nine, 433 from year nine to ten and 442 between the academic years ten and eleven. Numbers are slightly higher for the earlier years, but this merely reflects the general decline in mobility and is not social housing neighborhood specific.

\section{Descriptive statistics}

\section{Main dataset}

Table 1 contains summary statistics for the main dataset. The first two column pairs give information for pupils who either live in a social housing neighborhood throughout their academic years seven to eleven (columns 1), and for pupils who move into social housing neighborhoods during this period (columns 2). Column pairs (3) and (4) are for pupils who stay in a non-social housing neighborhood, and who move between nonsocial housing neighborhoods respectively. The table is further split into three panels, where panel A shows descriptive statistics on pupil characteristics, panel B on neighborhood characteristics, and panel $\mathrm{C}$ on school characteristics.

Column (1) shows descriptive statistics for the about 10,000 pupils who live in a highdensity social housing neighborhood during the whole period. We can see from panel A that these pupils have Key Stage test scores much below the national average, which is about fifty. Their KS2 scores average at only 38.64 points and the respective KS3 scores are even lower at 35.63 percentile points. These pupils are the weakest when starting secondary school, but results deteriorate even further up to KS3. Moreover, about half of them are eligible for free school meals (FSME), which is a proxy for a low-income background.

Still focusing on column pair (1), it further becomes evident from panel B that the neighborhoods where these pupils live are characterized by a very high average unemployment rate of almost twelve per cent, low qualification levels, room overcrowding, high building densities and low property prices. Only half of the households have access to a car or van, about one fifth of the household heads are lone parents with at least one dependent child, and forty-three per cent have at least one household member with a limiting long-term illness.

To summarize, pupils who live in social housing neighborhoods throughout the entire study period underperform at school, and their neighborhoods are characterized by indicators of high deprivation. 
Next, column (2) shows statistics for the 2,097 pupils who move into a social housing neighborhood during the study period. Panel A shows that they have individual characteristics very similar to pupils who live in a social housing neighborhood throughout. Their KS2 and KS3 test scores also average far below the national mean: at 37.258 and 33.332 respectively, they are even slightly lower compared to the 'stayers'. The only remarkable difference is in the share who change secondary school: about ten per cent of the 'movers' change school, compared to only 4.3 per cent of the 'stayers'. This suggests that controlling for school level characteristics will be important. As discussed, one general problem in neighborhood research is that neighborhoods do not change much over time. As a result I have to rely on movers to identify the effect. It is hence comforting to see that 'movers' are generally similar to 'stayers' with respect to their observable characteristics. This is important for the external validity of this study.

Panel B shows the respective neighborhood characteristics for these pupils. Note that these are the characteristics of the neighborhoods those pupils move out of, since I summarize area characteristics before the relocation. Pupils who move into social housing hence move out of the neighborhoods described in column (2), and into social housing neighborhoods described in column (1). We can see that the non-social-housing neighborhoods are significantly better than those of the social-housing-neighborhood stayers, something that we will examine in detail in table 2 below.

Columns (3) and (4) give summary statistics for pupils who lived in non-social housing neighborhoods throughout, or move between non-social housing neighborhoods respectively. Panel A shows that individual Key Stage scores are much higher compared to the social housing groups. Note, however, that movers (columns 4) have slightly lower scores than 'stayers' in non-social housing neighborhoods (47.064 compared to 51.317), but still much higher than the social housing groups (around 35). Also, only about fourteen to twenty per cent (compared to almost fifty per cent) of pupils in these nonsocial housing neighborhood groups are eligible for free school meals.

Secondly, panel B shows that non-social housing neighborhoods are much 'nicer' places to live, with unemployment rates around five per cent, high qualification levels, lower shares of lone parents with dependent children, about ten percentage points lower shares of residents with limiting long term illnesses, lower levels of overcrowding, larger homes, lower populations densities and higher house prices.

Finally, comparing panel $\mathrm{C}$ across columns and tables, it turns out that teacher-to-pupil ratios do not differ much for the various groups of pupils. 
To summarize, there are small differences between the 'mover' and 'stayer' groups, but it is evident that pupils who live in or move into social housing neighborhoods underperform in their KS2 and KS3 national tests. Furthermore, these areas present some of the most deprived neighborhoods in the UK.

\section{Descriptive statistics of neighborhood treatment}

As noted above, pupils who move into social housing neighborhoods experience deterioration in their neighborhood quality. Table 2 looks explicitly at the neighborhoodlevel changes that the 2,094 pupils who move into social housing neighborhoods experienced. The neighborhoods they move into are described in column (1) and column (2) gives the percentage change in neighborhood quality for each indicator compared to the neighborhood these pupils move out of. The first row of table 2 shows that unemployment rates are fifty per cent higher in the new social housing neighborhoods. In fact, we can see that neighborhood quality deteriorates in all characteristics for pupils who move into a social housing neighborhood. Pupils who move into a social housing neighborhood move into a neighborhood with a fifty-four per cent higher unemployment level, fourteen per cent lower qualification levels, twenty-three per cent lower access to a car or van, and fifty-six per cent more lone parents with dependent children. Furthermore, their new neighborhoods have fourteen per cent more inhabitants with limiting long-term illnesses, a twenty-eight per cent higher overcrowding index, ten per cent fewer rooms in the average household, twenty-nine per cent higher population density, and twenty-three per cent lower house prices. The third column of table 2 expresses these changes in terms of standard deviations. Overall, the changes experienced by social housing movers are substantial; they vary between a 0.3 to over 1.1 standard deviations of the underlying variables. Note that what this study identifies is the aggregate effect on school results that arises from this general deterioration in neighborhood quality. To summarize, table 2 shows that pupils who move into social housing neighborhoods experience significant deteriorations in their overall neighborhood quality. The next section presents the main results. 


\section{Results}

\section{A. 'Traditional'/OLS approach}

Before I turn to the main results, it is useful to inform the discussion with some benchmark regressions. These regressions are for comparative purpose only and do not focus on identification: they simply correlate KS3 results with the areas where the pupils live or move to. Table 3 shows the results from these regressions and is organized into two panels with three regressions each, where additional controls and school fixed effects are added subsequently in column (1) to (3) and (4) to (6). Panel A shows estimates for the effect on KS3 scores of living in a social housing neighborhood at the start of secondary education (year 7). In panel B the effect is estimated for pupils who move into social housing neighborhoods before the test in year 8 and 9. This is specification (1.1) from section II.

Turning to the estimates, panel A column (1) in table 3 shows the associations between living in a social housing neighborhood at the beginning of secondary education and KS3 scores. Without further controls, the estimate in the first row shows that pupils who lived in social housing neighborhoods in year 7 score 14.84 percentile points lower than their peers. This is an extremely strong association; it is hence not surprising that educational underperformance has been linked to neighborhood quality in the past. However, this association between place and test score reduces to about 2.9 percentile points once a rich set of controls including prior KS2 results are added (column 2). With school fixed effects, this association reduces further to 1.54 points, while remaining significant at the one-percentage level (column 3). Note that variables such as the number of years of free school meal eligibility - an income proxy - are more important in determining school improvements.

The results are similar in size and significance to panel B, which shows estimates for specification (1.1) discussed above. Here, the effects are estimated for pupils who move into a social housing neighborhood between the tests, hence for 'SH-movers' rather than for 'SH-stayers'. The unconditional association is now -13.251 percentile points (column 4) and it again reduces substantially, to 2.772 percentile points, once additional controls (column 5) and to 1.454 once school fixed effects (column 6) are added. These estimates are quite similar to panel A. If anything, the associations between moving into a social 
housing neighborhood and the test results are somewhat weaker compared to those who lived in social housing in year 7.

Summarizing the results from panels A and B: we see large and negative associations between neighborhood quality and school results. These associations reduce to about one and a half percentile points once controls for a rich set of background characteristics including previous test scores and school fixed effects are included. However, these neighborhood effect estimates are purely cross-sectional comparisons. As discussed earlier, unobserved correlated effects potentially bias these results. Therefore these results cannot be interpreted as causal effects.

\section{B. Main results: early and later movers into social housing neighborhoods}

Table 4 is divided into two panels horizontally and shows the main results. The upper part shows descriptive statistics (means) for groups moving before KS3/after KS3 and into social housing/non-social housing neighborhoods. Pupils who move into a social housing neighborhood before the test have average KS3 scores of 33.598, pupils who moved during the two years after the test score on average 32.962 (column 1). The corresponding figures for non-social-housing neighborhood movers are 46.849 and 45.847, as shown in column (2). In column (3) the first differences are shown for pupils either moving before or after the KS3 test. Pupils who move into social housing before the KS3 score 13.251 points worse than pupils who move between non-social-housing neighborhoods. Note that this simple difference in means is equivalent to the unconditional OLS-estimate presented in table 3 column (4). In the last column in panel A of table 4 I difference the first differences again, which results in the difference-indifferences of - $0.364 \mathrm{KS} 3$ points for pupils moving into social housing before versus after the test. This is equivalent to the unconditional difference-in-difference OLS estimate shown in the first column of panel B in table 4.

Panel B shows the estimates for specification (4) discussed in section II. Column (1) shows the unconditional estimate only controlling for a potential direct effect of moving, column (2) additionally includes previous test scores, ethnicity, school characteristics and gender, and in column (3) school fixed effects are added to the specification. Finally, in column (4) school fixed effects are replaced with neighborhood fixed effects.

The first row shows estimates for moving into a social housing neighborhood before the test $\gamma_{1}$, which are now non-significant in all specifications. The simple mean- 
difference-in-difference of -0.364 in columns (1) is not significantly different from zero. Adding controls, this causal estimate of moving into social housing before the KS3 test even turns positive in columns (2) to (4), and is estimated at $0.426,0.539$ and 0.267 respectively. However, none of these estimates is significantly different from zero at conventional levels. This result is in contrast to the cross-sectional estimates presented table 3. Importantly, it is not driven by increases in the standard errors but by actual changes in the absolute sizes of the estimates. ${ }^{15}$ This means that although pupils who move into a social housing neighborhood before the KS3 test underachieved, they did not underachieve to any different degree compared to their peers who move into a similar neighborhood after the KS3 test.

This becomes directly evident when we compare the 'traditional' estimates from table 3 with table 4. For example, column (4) from table 3 gives a negative association of 13.251 percentile points for early SH-movers. In table 4, this association is now fully captured by the dummy variable that controls for moving into social housing before or after the test $D(S H)_{i, t-1, t+1}$, which is estimated at -12.886 in the second row, panel $\mathrm{B}$, column (1). This strongly suggests that the previous negative associations between moving into social housing neighborhoods are driven by unobservable characteristics common among all pupils who move into social housing neighborhoods at some point, and not at all by exposure to social housing neighborhoods.

These conclusions are further substantiated in column (4), which includes neighborhood destination fixed effects. Here, the estimate in the first row shows the difference in KS3 results for pupils who moved into the same social housing neighborhood before or after the test. Again, there is no evidence for detrimental effects on test scores. This is an important finding because the neighborhood fixed effect absorbs any constant selection of groups or individuals into specific social housing neighborhoods, as well as for potential institutional discrimination. Note that the coefficient in row 2 , the pure association of test scores with moving into social housing neighborhoods at some point, is now also insignificant, which illustrates that the KS3 performance of 'SH-movers' does not generally differ from 'SH-stayers'.

${ }^{15}$ I cluster standard errors at the neighborhood level. Using robust standard errors instead does not alter any of the conclusions. 
To summarize the results, the traditional approach results in large and significant negative associations between living in or moving into social housing neighborhoods, and schooling. These associations persist despite the inclusion of a rich set of control variables including a test score measure of prior ability and school fixed effects. However, the difference-in-difference results show that the negative associations between moving into deprived social housing neighborhoods and test scores are driven by characteristics common to pupils who move into these neighborhoods at some point, and not by neighborhood exposure before taking the test. Using the timing of a move as source of exogenous variation, there is no evidence for detrimental short-term effects from moving into a deprived social housing neighborhood.

It is worth noting that the main findings hold for all specifications and are not at all sensitive to the inclusion of control variables such as previous test scores or fixed effects. This is a direct result of the strong balancing of individuals who move into social housing neighborhoods at different times. I will return to the issue of balancing in section V.

\section{Heterogeneity}

The previous section showed results for effects of general deteriorations in neighborhood quality. As already discussed in the section III (and table 2), pupils who move into social housing move into a neighborhood with higher unemployment levels, lower qualification rates, lower access to transport vehicles, a higher share of lone parents and people with a limiting long term illness, more overcrowding, fewer rooms per household, higher density and lower house prices. My results so far suggest that there is no overall effect on KS3 test scores of these 'treatments' combined. However, this finding does not preclude the possibility of heterogeneous effects. In this section, I present tests for potential heterogeneity in four different dimensions. ${ }^{16}$

Before discussing the findings of this exercise, I note that when allowing for heterogeneous effects in my difference-in-difference framework interactions need to be included for all relevant group variables. Therefore all regressions presented in table 5 include main interaction effects and interactions with the general moving dummies as well. This means that for each specification five additional terms are added: one main

\footnotetext{
${ }^{16}$ I tried further interactions but never found significant effects, which is why the discussion here is limited to four potential dimensions.
} 
effect, two in interaction with the general moving dummies, and two further interactions that are social-housing-move specific. In table 5, I only report the coefficients for the interactions with the social housing move, which are of main interest. Notice that I use the unconditional specification from table 4, column (1) as reference point in this exercise, although using additional control variables does not alter any of my conclusions below.

Column (1) of table 5 presents results for a regression that allows for a different treatment effect for pupils who move into a social housing neighborhood and also change secondary school. It is possible that lower neighborhood quality only matters if the school environment changes as well. If this is the case, then there should be significant differences between those two groups. Indeed, the estimate for the interactions between changing school and moving into social housing before the KS3 test is negative at 1.770 percentile points (first row). However, the standard error is very large and this estimate is not significant. $^{17}$

Next, I split the treatment by gender to allow for the possibility that boys and girls experience different effects. This is motivated by some of the recent literature finding gender differences in neighborhood effects. Kling (et al. 2005), for example, find different neighborhood effects for female and male youth on criminal activity. In column (2) I find a negative effect interaction effect for boys of -2.453 . To the contrary, the effect of moving before the KS3 test for females, now captured by the dummy indicating a preKS3 social housing move shown in the third row, is positive at 0.795 . Taken together, girls and boys could be affected differentially by up to three percentile points. However, again neither of the coefficients, nor the difference in these estimates, are significant in a statistical sense.

Finally, I consider interactions with continuous variables, namely the change in the neighborhood level unemployment rate (column 3) and the change in the percentage of lone parents with dependent children (column 4). Overall, pupils moving into social housing experiences large deteriorations in these indicators (see table 2). However, the estimates remain very close to zero: the interaction of a one percentage-point increase in the neighborhood unemployment-level change is estimated at 0.010 for pre-KS3 social

\footnotetext{
${ }^{17}$ Including school fixed effects moves this estimate closer to zero in magnitude (-0.66), remaining insignificant at any conventional level.
} 
housing movers. The corresponding coefficient for the lone parent indicator is estimated at -0.016 , very close to zero and also not significant despite relatively small standard errors $^{18}$.

To conclude the discussion on heterogeneous effects: interacting the difference-indifference framework with dichotomous indicators like school-changes or gender results in imprecise estimates that make it difficult to draw final conclusions. However, looking in detail for potential heterogeneity in continuous neighborhood level indicators, I fail to detect any significant results. In particular, there is no evidence of heterogeneity in the effect for changes in neighborhood level unemployment and the share of lone parents with dependent children. Overall, these results confirm the previous conclusions that there is no evidence for negative neighborhood effects for teenagers moving into social housing.

\section{Assessing the identification strategy}

\section{A. Balancing of individual and neighborhood characteristics: graphic analysis}

The identifying assumption of this study that early and late movers into social housing neighborhood are statistically identical. If early and late movers had different characteristics, this could potentially confound the analysis that links differences in exposure-times to social housing neighborhoods to school performance.

The data allows me to directly address this concern. Figure 3 shows averages of individual characteristics and neighborhood change for pupils moving into social housing neighborhoods, by year. Panel A shows the percentage of pupils who were eligible for free school meals in year 7, their gender and KS2 result. Notably, all these characteristics are determined before anyone moves and cannot be endogenous to the quality of the new neighborhoods. The figure clearly shows that pupils who move into social housing neighborhoods are very similar across the years. Regardless of the year, about fifty per cent are eligible for free school meals, slightly less than half are male and KS2 results average around thirty-four percentile points.

18 Not shown in the table for space reasons, I have also interacted the remaining neighborhood-level variables but equally failed to detect any significant patterns. The coefficient for moving early into social housing interacted with the change in the local unemployment rates is virtually zero, while interactions with overcrowding and qualification rates result in negative but very imprecisely measured effects. 
As discussed in section II.C., one potential threat to the identification might be that the timing of negative shocks that make parents eligible for social housing confounds the comparison of later test scores between early and later movers. If pre-move shocks had differential impacts on test scores, this should equally show up in the KS2. The fact that the KS2 results of early and late movers look extremely balanced is therefore particularly comforting.

In our setting, we can also check whether changes in neighborhood quality differ depending on the year of the move. This is another way to indirectly test for identification. I would expect the change in neighborhood quality (the underlying treatment) to be balanced with respect to the year of moving into a social housing neighborhood. Panel B of figure 3 shows the negative changes in neighborhood quality that pupils experience by year of move. What we can see is that the shocks are similar over the years. Regardless of the year of relocation, pupils move into neighborhoods with larger percentages of lone parents, more overcrowding, higher unemployment rates, lower qualification levels, lower access to cars and lower house prices. This further supports the causal interpretation of the social housing neighborhood effects in our setup.

\section{B. Balancing of individual and neighborhood characteristics}

\section{Probit regression analysis}

While the graphical analysis is reassuring, we can also test whether early movers differ from post-KS3 test movers into social housing neighborhoods formally using a probit regression. Here, $\operatorname{Pr}=1$ denotes the probability of moving into social housing in the years before the KS3, $\Phi$ the cumulative distribution function of the standard normal distribution (probit function), $X$ the matrix of regressors and $\beta$ the coefficients that are estimated by Maximum Likelihood.

$$
\operatorname{Pr}\left(D(S H)_{i, t-1, t+1}=1 \mid \mathbf{X}\right)=\phi\left(\mathbf{X}^{\prime} \boldsymbol{\beta}\right)
$$

Table 6 presents estimates of marginal effects for specification (8). The coefficients reported in column (1) are estimated using the 2,094 pupils who move into social housing at some point and the dependent variable equals one if the pupil moves before the KS3 test. If the identification assumption is violated, the KS2 score which correlates highly with the KS3 should be particularly prone to picking up differences between early and late movers. But as we can see from the marginal effects estimates in the first row of table 
6, early and late movers are literally identical with respect to previous attainment. This difference is estimated at -0.0097 and not statistically significant. Notice that similar conclusions hold for the other pre-determined variables like free school meal eligibility in year 7, gender or ethnicity, as shown by the remain estimates in column (1).

The second column presents estimates for 2,977 pupils who moved out of social housing during the study period. I have so far not explicitly focused on these pupils in the analysis because there are fewer reasons to believe that the timing of moving out of social housing could be exogenous. Essentially, this is because there are no waiting lists for moving out of social housing. However, even for these pupils, I cannot predict the year of move using a rich set of background variables including prior KS2 test scores.

Finally, the third column of table 6 shows that even non-social-housing neighborhood movers are quite balanced with regard to the timing of the move. For this group, there is a highly significant relation between KS2 test scores and the timing of the move, but the coefficient is small and estimated at 0.0173 . This means that each additional point in the KS2 test makes moving early 1.73 per cent more likely. This regression is estimated using over 106,427 pupils who move once and between non-social-housing neighborhoods during the study period, of which about fifty-six per cent actually move before the KS3. In other words, early non-social-housing neighborhood movers do better in terms of predetermined KS2 test scores, than late movers. Notice that this will bias me towards finding negative neighborhood effects for the social housing movers in the difference-indifference framework, which is not what I will find.

Another important assumption for the validity of the difference-in-difference approach is that there are no direct income effects resulting from moving into social housing (see section II.C.). If parents who move into social housing before the KS3 had a higher disposable income, this could counteract potential negative neighborhood influences. As I argued, this is unlikely in the English setting because housing benefits are administered in such a way as to net out income effects from moving into social housing, and I therefore do not think that the income channel is of particular importance for my setup. To test for this directly, table 6 also includesindicators for the free school meal status in the academic years 7 and 8 as regressors (second and third rows). These estimates are not significantly different to zero. This means that even free school meal eligibility in years 8 and 9, which are not a pre-determined measures for the early movers, fail to predict the timing of the move for social housing neighborhood movers (column 1). In other words, the time- 
sensitive free school meal indicator does not show any reaction to moving into social housing, which is comforting and in line with expectations.

To conclude the discussion of table 6 , in the last row I test the hypothesis that all coefficients jointly equal zero. It turns out that in column (1) I fail to reject the null for the social housing neighborhood movers. However, for non-social-housing neighborhood movers I can reject the null of joint insignificance, although the estimated coefficients are not very dissimilar in terms of magnitude (column (3)). Given these results, I therefore cannot completely rule out the possibility that that social housing neighborhood movers look balanced partly due to large standard errors. Notice, however, that the balancing test presented in table 6 is unconditional on school and neighborhood fixed effects.

\section{Balancing: OLS with fixed effects}

To investigate this possibility further I run additional balancing regressions where I can also include school fixed effects. Since pupils can in fact choose secondary schools relatively independently of residential location, sorting into schools does not need to be exactly correlated with the timing of the move. We know that there is a strong sorting mechanism in England; it would hence be comforting to look at the balancing conditional on school fixed effects. This can be done by running balancing regressions where individual characteristics (in particular the KS2 test scores) are used as a dependent variable and predicted by the timing of the move. This setup then allows us to keep the whole sample, including pupils who do not move, which in turn makes it possible to correctly estimate school fixed effects.

Table 7 reports estimates for such balancing regressions that use the KS2 test score as dependent variable. Column (1) and (3) report estimates for social-housing-neighborhood movers, while columns (2) and (4) focus on non-social-housing neighborhood moves, and columns (3) and (4) include school fixed effects. The estimates reported in column (3) come from the following specification:

$$
y_{\text {ignsct-1 }}=\kappa_{1} D(S H)_{i, t-1, t}+\kappa_{2} D(S H)_{i, t-1, t+1}+\mathbf{S}^{\prime} \kappa+c_{c}+\varepsilon_{\text {ignsct }}
$$

Where $y_{\text {ignsct-1 }}$ is the KS2 test result and the matrix $\mathbf{S}$ denotes dummy variables for each secondary school at enrolment in the academic year 7.The reported results in table 7 show that using the timing of the move as independent variable, OLS regressions on KS2 scores are not significant for SH-movers but again significant for non-SH movers. As 
before the signs are reversed, clearly indicating that $\mathrm{SH}$-movers are different to other movers at least with regard to the timing of moving. Once school fixed effects are included (columns (3) and (4)), the coefficient for moving into social housing neighborhoods before the KS3 stays insignificant and gets smaller and very close to zero, whereas the coefficient for non-SH-before-KS3-moves stays significant and becomes larger in size. Again, I read these results as supporting the identification assumption that the timing of $\mathrm{SH}$-moves is quasi-exogenous for social housing neighborhood movers, and in fact different to the timing behavior of non-social-housing neighborhood pupils. Of course, there might still be unobserved differences between these groups, but if unobservable characteristics positively correlate with observable characteristics (as in Altonji et al. 2005), then these balancing regressions can be interpreted as providing indirect evidence of the validity of the identification assumption.

\section{C.Identifying social housing neighborhood movers}

A data limitation of this study is that I am unable to exactly identify pupils who move into social housing neighborhoods. Instead, I need to rely on Output Area information from the UK 2001 Census of Population to determine if a neighborhood is social housing or not, as explained in Section III.B. Since only a handful of neighborhoods have onehundred per cent social tenants, all OAs with at least eighty per cent social tenants were classified as social housing neighborhoods. Note that neighborhood quality is negatively correlated with the threshold level. Neighborhoods with at least twenty per cent social tenants are worse than neighborhoods with at least ten per cent social tenants, but better than those with at least thirty per cent regarding the various neighborhood characteristics. I impose this somewhat arbitrary threshold to focus on pupils who move into neighborhoods with at least eighty per cent of social renters. This means that someone who moves from a neighborhood with seventy-nine per cent social renters to one with eighty-one per cent is now coded as 'moving into social housing'. Taking the regression from table 4 (column 4) as a benchmark, the first row of table 8 addresses this concern directly and only counts a move as into social housing if it was out of a neighborhood with a maximum of twenty per cent and into a neighborhood with at least eighty per cent social tenants. The results are insensitive to this modification, and we will return to table 8 later. 
Another way of testing if the choice of the threshold level influences the findings is to run separate regressions for different cut-off points. The sensitivity of the main result to the definition of this threshold is shown in figure 4. Panel A shows results for the traditional-approach regression as in table 3 (column 5), and panel B for the main results from table 4 (column 2), both for the specifications including school fixed effects. The dashed black line plots the estimates for the 'traditional' control strategy and the solid line for the difference-in-difference estimates. First, we can clearly see that the estimated negative neighborhood effect becomes larger as we increase the threshold in the 'traditional' approach. The estimated effect of moving from a neighborhood with less than ten per cent social tenants to a neighborhood with at least ten per cent is zero (panel A) or close to zero (panel B) but increases quickly in size and significance, shifting the threshold level up. The difference-in-difference estimate, on the other hand, remains constant around zero, suggesting that there is no neighborhood effect regardless of the definition of the threshold. This suggests that the increasing negative effects in the 'traditional' estimates reflect unobserved characteristics that correlate negatively with KS3 results and neighborhood quality. This is in line with the main finding that the negative association between neighborhood quality and school results disappears once controlling for moving into the social housing neighborhood at some point.

Finally, rather than just changing around the threshold of social housing tenants itself, I can further classify high-density social housing neighborhoods by their remaining share of owner occupiers. This is interesting for the following reason: high-density social housing neighborhoods with low share of owner occupation have higher shares of private rented accommodation. The skeptical reader might worry that if mobility is a lot higher in the private rented sector, then I might just pick up private movers into the remaining private rental market in high-density social housing neighborhoods rather than actual social housing movers. I can partly address this concern by focusing on high-density social housing neighborhoods that have a low remaining share of private rental, i.e. a high remaining share of owner occupation. Neighborhoods that have at least eighty per cent social tenants have remaining shares of owner occupation that vary between zero and twenty percent. The median is at about nine per cent owner occupation, the seventy-fifth percentile at about twelve per cent, the ninetieth percentile at fourteen and ninety-fifth percentile at sixteen per cent owner occupation. I use this information to recode the treatment variables and only assign "moving into social housing" if that neighborhood has a social rental share of over eighty per cent and at the same time an owner occupation 
share above the median, seventy-fifth, ninetieth and ninety-fifth percentile. Especially excluding movers who move into high-density social housing neighborhoods with very high owner occupation rates leaves very little room for private renters to cause the mobility patters that I see in the data. Makings these modifications I re-estimate all specifications of table 4 . Of the resulting sixteen coefficient only one is marginally significant at the five per cent level, and this coefficient is from an unconditional regression like table 4 column (1) and is positive. ${ }^{19}$ I therefore conclude that it is highly unlikely that movers in the private sector in neighborhoods with high social tenancy shares affect the interpretation of my results.

\section{Sample selection, imprecise measure of timing}

I further checked the sensitivity of the main finding against specific sample selection issues. These results are reported in table 8, where I only show the estimates of the main coefficient of interest, the effect of moving into social housing before the KS3.

As already discussed in the previous section, in the first row of table 8 I estimate specification (1) but now coding pupils as moving into social housing only, if they moved out of a neighborhood with a maximum of twenty per cent social tenants and into a neighborhood with at least eighty per cent. Again, there is no significant result, and early moves are even associated with a 0.400 -point increase in KS3 test scores, which is in line with my main findings.

Another concern is that the KS3 test is not taken on the exact date that residential information is collected. In particular, the residential information is collected mid of each January, while the KS3 is taken over the spring. This means that up to a third of pupils coded as moving in year nine to ten might in fact have moved just before the KS3 tests were taken, although residential mobility is usually lower during the winter period. In the second row of table 8, I therefore exclude from the analysis all pupils for whom I cannot be fully confident that they moved after the test was taken. This means that I compare KS3 test results of pupils who move into social housing neighborhoods in the academic years seven to eight or eight to nine to pupils who move into social housing neighborhoods in the years ten to eleven only. The estimates for this sample, negative 0.532 and insignificant, remains in line with our main results.

19 Table with all results available on request, omitted for space reasons. 
The third row estimates the specification using the first cohort only. All specifications include a cohort effect but this cohort effect is not interacted with all the other variables. If our results were cohort-specific this would cast serious doubts on the external validity of the findings. However, the effect of moving before the KS3 test is non-significant for both cohorts. As it turns out, for the first cohort, the estimate is negative and nonsignificant and for the second (not shown here) it is positive and insignificant. This strengthens the interpretation that there is no significant effect from moving into highdensity social housing neighborhoods.

Finally, the last row excludes 'stayers' from the regression. 'Stayers' were included to gain precision but their inclusion does not drive any the results, and the causal effect of moving before the KS3 is estimated at -0.013 points only.

\section{E. Different time windows and exposure times}

Another potential concern is that it takes longer for neighborhood effects to operate. To at least partially address this concern, table 9 includes pupils who move between the academic years six, which corresponds to the end of primary school, and year seven, the first year of secondary education. Hence, here we compare pupils who move into highdensity social housing neighborhoods during the three (not two) years prior to taking the KS3 test to pupils who move during the first two years after the test. The cost of this setup is that I can only use one cohort of pupils, which approximately halves the sample size.

Table 9 reports the results of this exercise and is organized in a similar way as the lower panel of the main results table 4. Two estimates are reported in the first row, where the first estimate is the effect of moving into social housing before the test, here between the academic years six and nine. The second row shows the coefficient for the dummy that indicates if a pupil moves into a social housing neighborhood at some point over the study period, here the extended period from academic year six to year eleven. Moving from columns (1) to (4), individual controls including KS2 test scores, school fixed effects and finally neighborhood fixed effects are included.

Just as in the main results table 4 , the estimate for the effect of moving into social housing before the KS3 test is never sizeable nor significant in any of the specifications. The unconditional estimate equals -0.990 , but turns positive to 0.883 once control variables are included, remains positive (0.864) in column (3) and becomes close to zero 
(0.083) once neighborhood fixed effects are included. Again, none of these estimates is significantly different from zero, and I conclude that moving into a social housing neighborhood during the three years prior to the KS3 test again does not correlate with the results.

Finally, to test if influences exist in earlier ages I replicated the analysis focusing on primary school years and pupils who move into social housing two years before or after taking the end-of-primary school KS2 test. Again, I find no evidence for neighborhood effects on educational outcomes.

\section{Conclusions}

This study estimates the effect of moving into a very deprived neighborhood, as identified by a high density of social housing, on the educational attainment of fourteenyear-old (ninth grade) students in England. Neighborhoods with markedly high concentrations of social housing have very high unemployment and extremely low qualification rates, as well as high building density, over-crowding and low house prices. In order to identify the causal impact of neighborhood deprivation on pupil attainments, I exploit the timing of moving into these neighborhoods. The timing of a move can be taken as exogenous because of long waiting lists for social housing in high-demand areas. Contrary to previous studies in the social housing context, this strategy does not rely on exogenous allocation of people to neighborhoods. Here, it is only required that the timing of such moves is unrelated to personal characteristics. This is a new strategy that bypasses the usual sorting and endogeneity problems. Using this approach, there is no evidence for otherwise negative short-term effects. This suggests that the existing and severe underachievement of pupils who move into social housing neighborhoods cannot be causally linked to place characteristics during the formative teenage years.

Besides its obvious relevance for policy, the finding of no effects supports the findings from the only experiment that addresses educational outcomes in the context of neighborhood effects. The Moving to Opportunity (MTO) experiment in the US. Katz (et al. 2001, 2007) and Ludwig (et al. 2012) does not find evidence for neighborhoodeffects on educational outcomes of teenagers.However, the MTO has been criticized for its intensity of treatment and geographical representativeness. Furthermore, the MTO compares movers to non-movers thus cannot control for a potential direct effect of moving. Notably, the findings of this study do not rely on a small set of neighborhoods 
or cities but are estimated using census data for the entire English secondary school population over two cohorts and neighborhoods in all areas of England. The neighborhood level treatments are large and I can also control for a direct of moving. Using the strategy to exploit the timing of the move, this is the first large-scale nonexperimental study that does not find evidence for neighborhood effects on educational outcomes, thus supporting the findings of the experimental literature. 


\section{Online Appendix}

\section{A1. The social housing sector in England}

The quality and social composition of social tenants has changed greatly over the past sixty years. After the Second World War, when Britain, like most other European countries, faced an acute housing shortage, social housing provided above-average quality accommodation. A move into social housing was regarded as moving up from private renting and most houses had gardens and good amenities (Lupton et al. 2009). The social housing sector continued to expand during the 1960s and 1970s and peaked at thirty-one per cent of the total English housing stock in 1979 (Hills 2007, p. 43). Social housing still provided much diversity in terms of both, quality and social and neighborhood composition but some of the older stock required refurbishments. As a response to this, housing associations, non-profit entities that provide social housing, started to grow in number and importance (Lupton et al. 2009).

From the 1980s until today the social sector shrank both in absolute size and importance relative to other types of tenure. Construction activity in the social sector declined sharply from almost 150,000 dwellings to 50,000 dwellings/year in the early 1980s and stagnate on the historically lowest level since the Second World War at around 20,000/year since the late 1990s (Hills 2007). In 2004, councils and housing associations provided about four million social dwellings (about eighteen per cent of stock), down from almost six million dwellings in 1979. This decline of social housing resulted from a combination of the 'right-to-buy' scheme introduced by Margaret Thatcher in 1980 and public spending cuts on new construction (Hills 2007, p. 125). The 'right-to-buy' scheme also altered the socioeconomic composition of social tenancy as it allowed those who could afford it move into owner-occupation (Hills 2007; Lupton et al. 2009). Admission criteria also changed during this period when the Homeless Persons Act of 1977 forced councils to provide accommodation to certain groups in extreme need (Holmans 2005). These trends continued through the 1980s and 1990s, and since 1991 growing demand has confronted a negative net supply of absolute numbers of social rented dwellings (Hills 2007). As a result of these changes and the increasingly needs-based allocation, in 2004 seventy per cent of social tenants belonged to the poorest two-fifths of the income distribution and hardly anyone to the richest fifth. This is in contrast to 1979 when twenty per cent of the richest decile lived in social housing (Hills 2007, pp. 45, 86). 
Today, demand for social housing greatly exceeds supply. Currently, nine million social renters live in four million social dwellings (Turley 2009). With very small but if anything negative net changes in social housing supply, spaces can only free up if existing tenants die or move out. Yet movement within or out of the sector is very low and eighty per cent of social tenants in 2007 were already there in 1998, if born (Hills 2007, p. 54). As a result, there are currently four-and-a-half million people (or about 1.8 million households) on waiting lists for social housing. Taking these numbers at face value, if nothing were to change and no one were born into social housing, this would mean that about 800,000 dwellings (twenty per cent of four million) could free up every ten years. Even assuming zero new demand over the coming years, it would take over twenty-two years to provide housing to all of those who are currently on a waiting list in this scenario.

The social housing allocation system as it exists today continues to operate on a needsbased system where the Homelessness Act 2002 defines beneficiaries. Importantly, families with children are treated as a priority. In the current situation of excess demand it is in fact very difficult to get into social housing without belonging to one of the needy groups. While the needy groups are defined nationally, provision is decentralized and administered through councils or housing associations. Local authorities operate different systems, some using a banding system and others a points-based system to ensure that those with the highest need and waiting time get a permanent place in social housing next (Hills 2007).

About a third of local authorities complement their waiting list system with a choicebased element, where new social housing places are announced publicly and prospective tenants are asked to show their interest in each specific place (Hills 2007, p. 163). The prospective tenant with the highest score as determined through the waiting list mechanisms then gets the offer. However, most places are still directly allocated through the council or housing association. Regan (et al. 2001) writes that one of their interviewees in Reading who rents from a social landlord complained: "Most of the people I know who have been offered flats or houses or anything have no choice... it is that or nothing" (2001, p.22). As I will argue later, it is not central to our identification that people cannot exert influence on the neighborhood or place where they are offered social housing.

As already mentioned, mobility within the social housing sector is extremely low. Reagan (ibid., executive summary, no page numbers) concludes in a qualitative study on housing choice and affordability in Reading and Darlington that "Moving within social 
housing was curtailed by allocation procedures and a lack of opportunity to move or swap properties". Quantitative evidence confirms that mobility within the social rented sector is extremely low, in spite of the mobility schemes that the government started to implement in the recent years (Hills 2007, p. 109). It is still the exception to move within the social housing sector once one gets in. An important point to take away from this discussion is that the social housing in England provides for a high degree of certainty or residential immobility.

Finally, there is a widespread perception that immigrants receive priority in social housing allocation. If this were true, changes in migration flows could confound my analysis. However, this is not the case because immigrants are generally ineligible for social housing, as pointed out by Rutter and Latorre (2009).

\section{A2. Housing Benefits}

In England, parents on low incomes or who are unemployed can claim housing benefit, which essentially covers part or up to one-hundred per cent of their payable rent. The eligibility rules over the study period were set in 1988 , which is prior to the period of this study (Hills 2007, p. 115) ${ }^{20}$. Importantly, housing benefits are awarded independently of tenure status and equally to parents living in the private rented or social housing sector or even in temporary private accommodation. The exact amount of housing benefit paid depends on a number of factors including the number of children, income and savings but also on the 'local reference rent', which is determined by local housing officials and effectively sets a maximum for what constitutes a 'reasonable' rent in the private sector. Depending on these circumstances housing benefits can cover the full rent. For central London, for example, the corresponding rent for a 2-room flat (i.e. one bedroom, one living room) was 290 pounds per week in December 2005 (Hills 2007, p.116). Importantly, housing benefits are responsive to residential changes or changes in rent; hence families who get offered a place and move into social housing where rents are fifty to sixty per cent lower than in the private rented sector will face an immediate and simultaneous reduction in housing benefits. This institutional setting gives rise to a unique situation where we do not expect any direct income effects from moving into social housing. I will return to the question of potential income effects from moving into social

\footnotetext{
${ }^{20}$ Recent changes to this policy following the last general election post-date the study period.
} 
housing in the robustness section, where I show that there is no significant association between free school meal status, an indicator for low income, and the timing of moving.

Notably, this institutional setting has some parallels to section 8 'tenant based' or 'project based' assistance in the US. Families in receipt of housing benefit in the private sector are in a similar situation like families receiving 'tenant based' section 8 assistance in respect to future mobility. On the other hand, social tenants in England benefit from stability like 'project based' section 8 tenants.

\section{REFERENCES}

Aaronson, D. (1998). Using sibling data to estimate the impact of neighborhoods on children's educational outcomes, Journal of Human Resources, pp. 915-46.

Ananat, E. (2007). The Wrong Side(s) of the Tracks: Estimating the Causal Effects of Segregation on City Outcomes. NBER Working Paper 13343.

Akerlof, G. (1997). Social Distance and Social Decisions, Econometrica, 65(5), pp. 1005-1027.

Altonji, G., T. Elder and C. Taber (2005). Selection on observed and unobserved variables: Assessing the effectiveness of Catholic schools, Journal of Political Economy, 113(1): pp. 151-184.

Bayer, P., Ross, S. L. \&Topa, G. (2008). Place of Work and Place of Residence: Informal Hiring Networks and Labour Market Outcomes, Journal of Political Economy, 116(6): pp. 1150-1196.

Bernheim, B.D. (1994). A Theory of Conformity, The Journal of Political Economy, 102(5), pp. 841-877.

Calvó-Armengol, A. \& Jackson, M.O. (2004). The Effects of Social Networks on Employment and Inequality, American Economic Review, 94(3), pp. 426-454.

Cheshire, P., Gibbons, S. \& Gordon, I. (2008). Policies for 'Mixed Communities': A Critical Evaluation, SERC Policy Paper, 2.

Clampet-Lundquist, S. \& Massey D. (2008) Neighborhood Effects on Economic SelfSufficiency: A Reconsideration of the Moving to Opportunity Experiment, American Journal of Sociology, 114(1), pp. 107-43.

Cutler, D.M. \& Glaeser, E.L. (1997). Are Ghettos Good Or Bad?*, The Quarterly Journal of Economics 112(3), pp. 827-72.

Durlauf, S. (1996). A Theory of Persistent Income Inequality, Journal of Economic Growth, I, pp. 75-93.

Fehr, E. \& Falk, A. (2002). Psychological foundations of incentives, European Economic Review, 46(4-5), pp. 687-724.

Figlio, D., Hamersma, S. \& Roth, J. (2011). Information Shocks and Social Networks, NBER Working Paper 16930.

Gibbons, S. (2002). Neighborhood effects on educational achievement: Evidence from the Census and National Child Development Study, Centre for the Economics of Education Discussion Paper, 16. 
Gibbons, S., Silva, O. \& Weinhardt, F. (2011). Everybody Needs Good Neighbors? Evidence from Students' Outcomes in England, IZA Discussion Papers 5980.

Glaeser, E. \&Scheinkman, J. (2001). Measuring Social Interactions, in Social Dynamics, Durlauf, S. \& Young, P. (eds.), Boston,MA: MITPress.

Gould, E.D., Lavy, V. \&Pasterman M.D. (2004). Immigrating to Opportunity: Estimating the Effect of School Quality using a Natural Experiment on Ethiopians in Israel, The Quarterly Journal of Economics 119(2): 489-526.

Goux, D. \&Maurin, E. (2007). Close neighbors matter: neighborhood effects on early performance at school, Economic Journal, 117(523), pp. 1193-215.

Granovetter, M., (1995): Getting a Job, second edition, Chicago, IL: University of Chicago Press.

Gurmu, S., Ihlanfeldt, K.R. \& Smith, W.J. (2008). Does residential location matter to the employment of TANF recipients? Evidence from a dynamic discrete choice model with unobserved effects, Journal of Urban Economics, 63, pp. 325-351.

Hills, J. (2007). Ends and Means: The future roles of social housing in England, Report: London School of Economics and Political Science, CASEreport 34.

Hobbs, G. \&Vignoles, A. (2007). Is free school meal status a valid proxy for socio-economic status (in schools research)?, Centre for Economics of Education Discussion Paper, 84.

Holmans, A. (2005). Housing and Housing Policy in England 1975-2002, Report: Office of the Deputy Prime Minister, London.

Jacob, B.A. (2004), Public housing, housing vouchers, and student achievement: Evidence from public housing demolitions in Chicago, The American Economic Review, 94(1), pp. 233-58.

Katz, L.F., Kling, J.R. \&Liebman, J.B. (2001). Moving to Opportunity in Boston: Early Results of a Randomized Mobility Experiment, The Quarterly Journal of Economics 116 (May 2001), 607-54.

Kling, J., Ludwig, J. \& Katz, L. (2005). Neighborhood Effects on Crime for Female and Male Youth: Evidence From a randomized Housing Voucher Experiment, Quarterly Journal of Economics, 120, pp. 87-130.

Kling, J R, J B Liebman, and L F Katz. (2007) Experimental Analysis of Neighbourhood Effects, Econometrica 120(1), pp. 83-119.

Ludwig, J., Duncan, G., Gennetian, L., Katz, L., Kessler, R., Kling J \&Sanbonmatsu, L. (2012) Neighborhood Effects on the Long-Term Well-Being of Low-Income Adults, Science, 337(21), pp. 1505-10.

Lupton, R. (2005). Social justice and school improvement: improving the quality of schooling in the poorest neighborhoods, British Educational Research Journal, 31(5), pp. 589-604.

Lupton, R., Tunstall, R., Sigle-Rushton, W., Obolenskaya P., Sabates, R., Meschi, E., Kneale, D. \& Salter, E. (2009). Growing up in social housing in Britain, Report: Joseph Rowntree Foundation, York.

Manski, C.F. (1993). Identification of endogenous social effects: The reflection problem, The Review of Economic Studies, 60(3), pp. 531-42.

Moffitt, R.A. (2001). Policy interventions, low-level equilibria, and social interactions, in Social Dynamics, Durlauf, S. \& Young, P. (eds.), Boston,MA: MITPress. 
Oreopoulos, P. (2003). The Long-Run Consequences of Living in a Poor Neighborhood*, The Quarterly Journal of Economics, 118(4), pp. 1533-1575

Quigley, J. \& Raphael, S. (2008). Neighborhoods, Economic Self-Sufficiency, and the MTO Program. Brookings-Wharton Papers on Urban Affairs, 7, pp. 1-46.

Small, M. (2009). Unanticipated Gains: Origins of Network Inequality in Everyday Life, Oxford University Press.

Small, M. \& Jacobs, E. (2008). Why Organizational Ties Matter for Neighborhood Effects: Resource Access through Childcare Centers, Social Forces, 87(1), pp. 387-414.

Regan, S. \& Patrick, R. (2001). Squeezed Out, Institute for Public Policy Research, London.

Ross, S. (1998). Racial Differences in Residential and Job Mobility. Journal of Urban Economics, 43, 112-36.

Ross, S. (2011). Social interactions within cities: Neighbourhood environments and peer relationships, in Handbook of Urban Economics and Planning, Brooks, N., Donaghy, K. \& Knapp, G. (eds.), Oxford University Press.

Rothstein, J. (2010). Teacher Quality in Educational Production: Tracking, Decay, and Student Achievement, The Quarterly Journal of Economics, 125(1), pp. 175-214.

Rutter, J. \&Latorre, M. (2009). Social housing allocation and immigrant communities, Report: Institute for Public Policy Research, London.

Sanbonmatsu, L., Kling, J.R., Duncan, G.J. \& Brooks-Gunn, J. (2006). Neighborhoods and academic achievement: Results from the Moving to Opportunity Experiment, Journal of Human Resources, 41(4), p. 649.

Small, M., \& Feldman, J. (2012). Ethnographic Evidence, Heterogeneity, and Neighbourhood Effects After Moving to Opportunity, in Neighbourbood Effects Research: New Perspectives, van Ham, M., Manley, D., Bailey, N., Simpson, L. and Maclennan, D. (eds.), Dordrecht: Springer, 2012.

Todd, P. \&Wolpin, K. (2003). On the specification and estimation of the production function for cognitive achievement, The Economic Journal, 113(485), pp. F3-F33.

Turley (2009). Council Housing -Back to the Future?, Report: New Local Government Network, London.

Weinberg, B. (2004). Testing the Spatial Mismatch Hypothesis Using Inter-city Variations in Industrial Composition. Regional Science and Urban Economics, 34(5): 505-32.

Weinberg, B. (2000). Black Residential Centralization and the Spatial Mismatch Hypothesis. Journal of Urban Economics, 48, 110-34.

Weinhardt, F. (2010) Moving into the Projects: Social Housing Neighbourhoods and School Performance in England. SERC Discussion Paper\#44.

Zenou, Y. (2008). Social Interactions and Labour Market Outcomes in Cities, IZA Discussion Paper 3283. 
(1)

Pupil stayed in

SH n'hood during study period

(2)

(3)

(4)

Pupil moved into SH n'hood during study period

Pupil stayed in non-SH n'hood during study period

Mean s.d. Mean s.d. Mean s.d. period

Pupil moved btw. non-SH n'hoods during study

Mean s.d.

Panel A: Individual characteristics

Key Stage 2 Score
Key Stage 3 Score
Changed school before, yr 7-9
FSME eligibility year 7
FSME eligibility year 8
FSME eligibility year 9
Gender (male=1)
Ethnicity-White British Is.
Ethnicity-Other White
Ethnicity-Asian
Ethnicity-Black
Ethnicity-Chinese
Ethnicity-Mixed
Ethnicity-Other

$\begin{array}{rrrrrrrr}38.641 & 24.229 & 37.258 & 24.332 & 51.317 & 25.902 & 47.064 & 25.685 \\ 35.629 & 23.721 & 33.332 & 23.710 & 51.507 & 26.439 & 46.409 & 26.111 \\ 0.043 & 0.202 & 0.106 & 0.308 & 0.021 & 0.144 & 0.095 & 0.293 \\ 0.494 & 0.500 & 0.498 & 0.500 & 0.143 & 0.350 & 0.205 & 0.404 \\ 0.484 & 0.500 & 0.494 & 0.500 & 0.139 & 0.346 & 0.197 & 0.398 \\ 0.467 & 0.499 & 0.493 & 0.500 & 0.133 & 0.340 & 0.187 & 0.390 \\ 0.500 & 0.500 & 0.484 & 0.500 & 0.508 & 0.500 & 0.497 & 0.500 \\ 0.629 & 0.483 & 0.694 & 0.491 & 0.830 & 0.376 & 0.804 & 0.397 \\ 0.036 & 0.187 & 0.032 & 0.176 & 0.017 & 0.130 & 0.020 & 0.139 \\ 0.065 & 0.246 & 0.053 & 0.223 & 0.066 & 0.248 & 0.065 & 0.247 \\ 0.166 & 0.372 & 0.138 & 0.345 & 0.030 & 0.169 & 0.044 & 0.205 \\ 0.008 & 0.088 & 0.007 & 0.082 & 0.003 & 0.055 & 0.003 & 0.054 \\ 0.043 & 0.203 & 0.036 & 0.187 & 0.021 & 0.145 & 0.025 & 0.156 \\ 0.028 & 0.164 & 0.019 & 0.137 & 0.006 & 0.080 & 0.010 & 0.098\end{array}$

Panel B: Neighborhood characteristics, pre move (if any)

\begin{tabular}{|c|c|c|c|c|c|c|c|c|}
\hline Unemployment rate & 0.117 & 0.048 & 0.079 & 0.045 & 0.045 & 0.037 & 0.054 & 0.042 \\
\hline Level $4+$ qualification ${ }^{1}$ & 0.489 & 0.114 & 0.548 & 0.130 & 0.618 & 0.131 & 0.603 & 0.133 \\
\hline Access to car or van ${ }^{2}$ & 0.500 & 0.128 & 0.649 & 0.169 & 0.830 & 0.151 & 0.787 & 0.167 \\
\hline Lone parent with dep. child & 0.199 & 0.090 & 0.124 & 0.070 & 0.073 & 0.100 & 0.087 & 0.066 \\
\hline Limiting long term illness & 0.431 & 0.100 & 0.386 & 0.098 & 0.344 & 0.100 & 0.351 & 0.103 \\
\hline Overcrowding 3 & 0.198 & 0.131 & 0.132 & 0.110 & 0.066 & 0.076 & 0.081 & 0.086 \\
\hline Number of rooms & 4.291 & 0.537 & 4.782 & 0.648 & 5.439 & 0.824 & 5.230 & 0.797 \\
\hline Population density ${ }^{4}$ & 133.978 & 158.608 & 86.643 & 91.936 & 53.187 & 49.823 & 61.066 & 62.365 \\
\hline Average house price 5 & 0.617 & 0.630 & 0.716 & 0.496 & 0.931 & 0.537 & 0.840 & 0.499 \\
\hline \multicolumn{9}{|c|}{ Panel C: Secondary school characteristics, year 7} \\
\hline Pupil to teacher ratio & 15.734 & 1.856 & 15.877 & 1.808 & 15.850 & 1.555 & 15.894 & 1.601 \\
\hline
\end{tabular}


Table 2: Neighbourhood quality treatment

\begin{tabular}{|c|c|c|c|}
\hline & (a) & (b) & (c) \\
\hline & New SH n'hood & \% ch. & S.D.ch. \\
\hline Unemployment rate & 0.122 & $54.43 \%$ & 1.089 \\
\hline Level 4+ qualification & 0.470 & $-14.08 \%$ & -0.589 \\
\hline Access to car or van & 0.497 & $-23.42 \%$ & -0.947 \\
\hline Lone parent with dep. child & 0.194 & $56.45 \%$ & 1.116 \\
\hline Limiting long term illness & 0.441 & $14.25 \%$ & 0.542 \\
\hline Overcrowding & 0.169 & $28.03 \%$ & 0.453 \\
\hline Number of rooms & 4.333 & $-9.39 \%$ & -0.540 \\
\hline Population density & 112.151 & $29.44 \%$ & 0.446 \\
\hline Average house price & 0.550 & $-23.08 \%$ & -0.312 \\
\hline
\end{tabular}

Notes: Only pupils who always lived in a Local Authority with more than $5 \%$ of population on Social Housing waiting list included. 2,094 obs. Variables defined as in previous Tables.

Table 3: Social housing and school performance, traditional approach: OLS

\begin{tabular}{|c|c|c|c|c|c|c|}
\hline \multirow[b]{3}{*}{ Dependent variable: KS3 } & \multicolumn{3}{|c|}{$\underline{\text { Panel A }}$} & \multicolumn{3}{|c|}{$\underline{\text { Panel B }}$} \\
\hline & \multicolumn{3}{|c|}{ Lived in SH neighborhood in year 7} & \multicolumn{3}{|c|}{ Moved into SH neighborhood before KS3 test } \\
\hline & (1) & (2) & (3) & (4) & (5) & (6) \\
\hline $\begin{array}{l}\text { Estimated effect on Key } \\
\text { Stage } 3 \text { score: }\end{array}$ & $\begin{array}{l}-14.837 \\
(0.260)^{* *}\end{array}$ & $\begin{array}{l}-2.899 \\
(0.161)^{* *}\end{array}$ & $\begin{array}{l}-1.540 \\
(0.140)^{* *}\end{array}$ & $\begin{array}{l}-13.251 \\
(0.703)^{* *}\end{array}$ & $\begin{array}{l}-2.722 \\
(0.413)^{* *}\end{array}$ & $\begin{array}{l}-1.454 \\
(0.373)^{* *}\end{array}$ \\
\hline Key Stage 2 score & - & $\begin{array}{l}0.849 \\
(0.001)^{\star *}\end{array}$ & $\begin{array}{l}0.820 \\
(0.001)^{* *}\end{array}$ & - & $\begin{array}{l}0.850 \\
(0.001)^{* *}\end{array}$ & $\begin{array}{l}0.820 \\
(0.001)^{* *}\end{array}$ \\
\hline $\begin{array}{l}\text { Changed secondary school } \\
\text { before KS3 }\end{array}$ & - & $\begin{array}{l}-3.060 \\
(0.107)^{* *}\end{array}$ & $\begin{array}{l}-1.669 \\
(0.115)^{* *}\end{array}$ & - & $\begin{array}{l}-3.252 \\
(0.107)^{* *}\end{array}$ & $\begin{array}{l}-1.854 \\
(0.006)^{\star *}\end{array}$ \\
\hline FSME eligibility year 7 & - & $\begin{array}{l}-2.935 \\
(0.091)^{* *}\end{array}$ & $\begin{array}{l}-1.920 \\
(0.087)^{* *}\end{array}$ & - & $\begin{array}{l}-3.005 \\
(0.092)^{* *}\end{array}$ & $\begin{array}{l}-1.948 \\
(0.087)^{\star *}\end{array}$ \\
\hline FSME eligibility year 8 & - & $\begin{array}{l}-1.468 \\
(0.112)^{* *}\end{array}$ & $\begin{array}{l}-0.991 \\
(0.106)^{* *}\end{array}$ & - & $\begin{array}{l}-1.494 \\
(0.112)^{* *}\end{array}$ & $\begin{array}{l}-0.999 \\
(0.106)^{* *}\end{array}$ \\
\hline FSME eligibility year 9 & - & $\begin{array}{l}-2.118 \\
(0.097)^{* *}\end{array}$ & $\begin{array}{l}-1.459 \\
(0.092)^{* *}\end{array}$ & - & $\begin{array}{l}-2.162 \\
(0.097)^{* *}\end{array}$ & $\begin{array}{l}-1.469 \\
(0.092)^{* *}\end{array}$ \\
\hline Gender $($ male $==1)$ & - & $\begin{array}{l}-1.411 \\
(0.035)^{\star *}\end{array}$ & $\begin{array}{l}-1.249 \\
(0.036)^{* *}\end{array}$ & - & $\begin{array}{l}-1.412 \\
(0.035)^{\star *}\end{array}$ & $\begin{array}{l}-1.251 \\
(0.036)^{\star *}\end{array}$ \\
\hline Pupil to teacher ratio, y. 7 & - & $\begin{array}{l}-0.499 \\
(0.014)^{* *}\end{array}$ & (absorbed) & - & $\begin{array}{l}-0.497 \\
(0.014)^{* *}\end{array}$ & (absorbed) \\
\hline Control for moving into $\mathrm{SH}$ & No & No & No & No & No & No \\
\hline Controls for moving & Yes & Yes & Yes & Yes & Yes & Yes \\
\hline Ethnicity-controls & No & Yes & Yes & No & Yes & Yes \\
\hline School fixed effects & No & No & Yes & No & No & Yes \\
\hline
\end{tabular}

Notes: Neighborhood classified as Social housing if at least $80 \%$ of residents in social rented sector. Over 596k obs., errors clustered at neighborhood level. Only pupils who always lived in Local Authority with more than $5 \%$ of population on Social Housing waiting list. Standard errors in brackets. ** sig. at $1 \%$. 
Table 4: Main results: social housing and school performance, the causal effect

\begin{tabular}{|c|c|c|c|c|}
\hline & (1) & (2) & (3) & (4) \\
\hline Dependent variable: KS3 test scores & $\begin{array}{l}\text { Moved into } \\
\text { SH n'hood }\end{array}$ & $\begin{array}{c}\text { Moved into } \\
\text { non-SH } \\
\text { n'hood }\end{array}$ & $\begin{array}{c}\text { First } \\
\text { Difference }\end{array}$ & DiD \\
\hline \multicolumn{5}{|l|}{ Panel A: Unconditional means } \\
\hline Move before KS3 test & 33.598 & 46.849 & -13.251 & \multirow{2}{*}{-0.365} \\
\hline Move after KS3 test & 32.962 & 45.847 & -12.886 & \\
\hline \multicolumn{5}{|l|}{ Panel B: Regression estimates } \\
\hline Move into SH neighborhood before KS3 test & $\begin{array}{l}-0.365 \\
(1.056)\end{array}$ & $\begin{array}{c}0.426 \\
(0.628)\end{array}$ & $\begin{array}{c}0.539 \\
(0.597)\end{array}$ & $\begin{array}{c}0.267 \\
(0.651)\end{array}$ \\
\hline Move into SH neighborhood before or after KS3 test & $\begin{array}{l}-12.886 \\
(0.801)^{* *}\end{array}$ & $\begin{array}{l}-3.152 \\
(0.481)^{* *}\end{array}$ & $\begin{array}{l}-2.000 \\
(0.454)^{* *}\end{array}$ & $\begin{array}{c}0.097 \\
(0.515)\end{array}$ \\
\hline Key Stage 2 score & - & $\begin{array}{l}0.850 \\
(0.001)^{* *}\end{array}$ & $\begin{array}{c}0.820 \\
(0.001)^{* *}\end{array}$ & $\begin{array}{c}0.830 \\
(0.001)^{* *}\end{array}$ \\
\hline Changed secondary school before KS3 & - & $\begin{array}{l}-3.251 \\
(0.107)^{* *}\end{array}$ & $\begin{array}{l}-1.854 \\
(0.116)^{* *}\end{array}$ & $\begin{array}{l}-2.763 \\
(0.120)^{* *}\end{array}$ \\
\hline FSME eligibility year 7 & - & $\begin{array}{l}-3.001 \\
(0.092)^{* *}\end{array}$ & $\begin{array}{l}-1.946 \\
(0.087)^{* *}\end{array}$ & $\begin{array}{l}-1.439 \\
(0.101)^{* *}\end{array}$ \\
\hline FSME eligibility year 8 & - & $\begin{array}{l}-1.494 \\
(0.112)^{* *}\end{array}$ & $\begin{array}{l}-1.466 \\
(0.092)^{* *}\end{array}$ & $\begin{array}{l}-0.924 \\
(0.123)^{* *}\end{array}$ \\
\hline FSME eligibility year 9 & - & $\begin{array}{l}-2.156 \\
(0.097)^{* *}\end{array}$ & $\begin{array}{l}-1.466 \\
(0.092)^{* *}\end{array}$ & $\begin{array}{l}-1.058 \\
(0.107)^{* *}\end{array}$ \\
\hline Gender $($ male $==1)$ & - & $\begin{array}{l}-1.412 \\
(0.035)^{* *}\end{array}$ & $\begin{array}{l}-1.251 \\
(0.036)^{* *}\end{array}$ & $\begin{array}{l}-1.525 \\
(0.040)^{* *}\end{array}$ \\
\hline Pupil to teacher ratio, year 7 & - & $\begin{array}{l}-0.497 \\
(0.014)^{* *}\end{array}$ & (absorbed) & $\begin{array}{l}-0.549 \\
(0.019)^{* *}\end{array}$ \\
\hline Control for moving into social housing & Yes & Yes & Yes & Yes \\
\hline Controls for effects of moving & Yes & Yes & Yes & Yes \\
\hline Ethnicity-controls & No & Yes & Yes & Yes \\
\hline School fixed effects & No & No & Yes & No \\
\hline Output Area fixed effects (after move) & No & No & No & Yes \\
\hline
\end{tabular}

Notes: Neighborhoods classified as Social housing if at least $80 \%$ of residents in social rented sector. SH movers who move only once. Only pupils who always lived in Local Authority with more than $5 \%$ of population on Social Housing waiting list. Over 596k obs., errors clustered at neighborhood level. Standard errors in brackets. ${ }^{*}$ sig. at $1 \%$. 


\begin{tabular}{|c|c|c|c|c|}
\hline & (1) & (2) & (3) & (4) \\
\hline Dependent variable: $\mathrm{KS} 3$ test scores & $\begin{array}{c}\text { Changed } \\
\text { School } \\
\text { before KS3 }\end{array}$ & $\begin{array}{l}\text { Gender } \\
(\text { male }=1)\end{array}$ & $\begin{array}{l}\text { Change in } \\
\text { n'hood \% } \\
\text { unemp't. }\end{array}$ & $\begin{array}{c}\text { Change in } \\
\text { n'hood \% } \\
\text { lone } \\
\text { parents }\end{array}$ \\
\hline $\begin{array}{l}\text { Interaction * Move into SH n'hood } \\
\text { before KS3 }\end{array}$ & $\begin{array}{l}-1.770 \\
(4.220)\end{array}$ & $\begin{array}{l}-2.453 \\
(2.128)\end{array}$ & $\begin{array}{c}0.010 \\
(0.169)\end{array}$ & $\begin{array}{l}-0.016 \\
(0.097)\end{array}$ \\
\hline $\begin{array}{l}\text { Interaction* Move into SH n'hood } \\
\text { before or after KS3 }\end{array}$ & $\begin{array}{c}1.368 \\
(3.790)\end{array}$ & $\begin{array}{c}2.536 \\
(1.620)\end{array}$ & $\begin{array}{c}0.020 \\
(0.127)\end{array}$ & $\begin{array}{l}-0.021 \\
(0.074)\end{array}$ \\
\hline $\begin{array}{l}\text { Move into SH neighborhood } \\
\text { before KS3 }\end{array}$ & $\begin{array}{l}-0.359 \\
(1.10)\end{array}$ & $\begin{array}{c}0.795 \\
(1.462)\end{array}$ & $\begin{array}{l}-0.114 \\
(1.269)\end{array}$ & $\begin{array}{c}0.324 \\
(1.250)\end{array}$ \\
\hline $\begin{array}{l}\text { Move into SH neighborhood } \\
\text { before or after KS3 }\end{array}$ & $\begin{array}{l}-12.801 \\
(0.816)^{* *}\end{array}$ & $\begin{array}{l}-14.124 \\
(1.085)^{* *}\end{array}$ & $\begin{array}{l}-13.838 \\
(0.980)^{* *}\end{array}$ & $\begin{array}{l}-13.731 \\
(0.926)^{* *}\end{array}$ \\
\hline Control for moving into social housing & Yes & Yes & Yes & Yes \\
\hline Controls for effects of moving & Yes & Yes & Yes & Yes \\
\hline Ethnicity-controls & No & No & No & No \\
\hline School fixed effects & No & No & No & No \\
\hline Output Area fixed effects (after move) & No & No & No & No \\
\hline
\end{tabular}

Notes: Baseline regressions is Table 4 (column 1). Interaction main effects and for non-SH movers always included (coefficients not reported here). Neighborhoods classified as social housing if at least $80 \%$ of residents in social rented sector. Movers only move once. Only pupils who always lived in Local Authority with more than $5 \%$ of population on Social Housing waiting list. Over $596 \mathrm{k}$ obs., errors clustered at neighborhood level. Standard errors in brackets. ${ }^{* *}$ sig. at $1 \%$. 
Table 6: Probability of moving in the two years before versus after the KS3 test

\begin{tabular}{|c|c|c|c|}
\hline & (1) & (2) & (3) \\
\hline & $\begin{array}{l}\text { Moving into } \\
\text { SH n'hood }\end{array}$ & $\begin{array}{l}\text { Moving out } \\
\text { of SH n'hood }\end{array}$ & $\begin{array}{l}\text { Non-SH } \\
\text { n'hood move }\end{array}$ \\
\hline Key Stage 2 score & $\begin{array}{l}-0.0097 \\
(0.044)\end{array}$ & $\begin{array}{l}-0.0076 \\
(0.039)\end{array}$ & $\begin{array}{c}0.0173 \\
(0.006)^{* *}\end{array}$ \\
\hline FSME eligibility year 7 & $\begin{array}{l}-0.030 \\
(0.033)\end{array}$ & $\begin{array}{c}0.015 \\
(0.028)\end{array}$ & $\begin{array}{l}0.024 \\
(0.006)^{* *}\end{array}$ \\
\hline FSME eligibility year 8 & $\begin{array}{c}0.051 \\
(0.038)\end{array}$ & $\begin{array}{c}0.009 \\
(0.331)\end{array}$ & $\begin{array}{l}-0.004 \\
(0.008)\end{array}$ \\
\hline FSME eligibility year 9 & $\begin{array}{c}0.006 \\
(0.032)\end{array}$ & $\begin{array}{l}-0.037 \\
(0.029)\end{array}$ & $\begin{array}{l}-0.016 \\
(0.007)^{* *}\end{array}$ \\
\hline Gender $($ male $==1)$ & $\begin{array}{c}0.011 \\
(0.021)\end{array}$ & $\begin{array}{l}-0.011 \\
(0.018)\end{array}$ & $\begin{array}{l}0.012 \\
(0.003)^{* *}\end{array}$ \\
\hline Ethnicity-White British Isles & $\begin{array}{c}0.121 \\
(0.075)\end{array}$ & $\begin{array}{c}0.046 \\
(0.062)\end{array}$ & $\begin{array}{c}0.009 \\
(0.009)\end{array}$ \\
\hline Ethnicity-Other White & $\begin{array}{c}0.051 \\
(0.093)\end{array}$ & $\begin{array}{l}-0.024 \\
(0.086)\end{array}$ & $\begin{array}{c}0.006 \\
(0.014)\end{array}$ \\
\hline Ethnicity-Asian & $\begin{array}{c}0.130 \\
(0.080)\end{array}$ & $\begin{array}{c}0.009 \\
(0.073)\end{array}$ & $\begin{array}{l}0.021 \\
(0.011)^{\$}\end{array}$ \\
\hline Ethnicity-Black & $\begin{array}{c}0.121 \\
(0.073)\end{array}$ & $\begin{array}{l}-0.041 \\
(0.066)\end{array}$ & $\begin{array}{c}0.006 \\
(0.012)\end{array}$ \\
\hline Ethnicity-Chinese & $\begin{array}{c}0.163 \\
(0.127)\end{array}$ & $\begin{array}{l}-0.134 \\
(0.158)\end{array}$ & $\begin{array}{c}0.010 \\
(0.030)\end{array}$ \\
\hline Ethnicity-Mixed & $\begin{array}{l}-0.228 \\
(0.095)\end{array}$ & $\begin{array}{c}0.074 \\
(0.073)\end{array}$ & $\begin{array}{l}-0.001 \\
(0.013)\end{array}$ \\
\hline Ethnicity-Other & $\begin{array}{l}-0.001 \\
(0.006)\end{array}$ & $\begin{array}{l}-0.080 \\
(0.096)\end{array}$ & $\begin{array}{c}0.005 \\
(0.018)\end{array}$ \\
\hline Teacher to pupil ratio (y7) & $\begin{array}{l}-0.001 \\
(0.006)\end{array}$ & $\begin{array}{c}0.002 \\
(0.006)\end{array}$ & $\begin{array}{l}-0.002 \\
(0.001)^{*}\end{array}$ \\
\hline Cohort & $\begin{array}{l}-0.010 \\
(0.022)\end{array}$ & $\begin{array}{l}-0.026 \\
(0.019)\end{array}$ & $\begin{array}{l}-0.022 \\
(0.003)^{* *}\end{array}$ \\
\hline School FX & No & No & No \\
\hline H0: All coefficients equal zero. Prob $>$ chi2 & 0.2996 & 0.1461 & 0.000 \\
\hline
\end{tabular}

Notes: Dependent variable equals one if pupil move before KS3 in sample where everyone move once and into Social Housing neighborhoods, hence either before or after KS3. (a): 2,094 obs.; (b): 2,977 obs.; (c): over 105,000 obs. Probit regression, marginal effects. Standard errors in brackets and clustered at neighborhood level. Only pupils who always lived in Local Authority with more than 5 per cent of population on Social Housing waiting list included. 
Table 7: Balancing regressions by type of move

\begin{tabular}{|c|c|c|c|c|}
\hline Dependent Variable: & (1) & (2) & (3) & (4) \\
\hline $\mathrm{KS} 2$ test scores & $\begin{array}{l}\text { Moving into SH } \\
\text { n'hood, OLS }\end{array}$ & $\begin{array}{c}\text { Non-SH n'hood } \\
\text { move, OLS }\end{array}$ & $\begin{array}{c}\text { Moving into SH } \\
\text { n'hood }\end{array}$ & $\begin{array}{l}\text { Non-SH n'hood } \\
\text { move }\end{array}$ \\
\hline Move before KS3 & $\begin{array}{l}-0.437 \\
(1.082)\end{array}$ & $\begin{array}{c}0.396 \\
(0.159)^{*}\end{array}$ & $\begin{array}{c}0.092 \\
(1.053)\end{array}$ & $\begin{array}{l}0.443 \\
(0.148)^{* *}\end{array}$ \\
\hline Move & $\begin{array}{l}-12.802 \\
(0.824)^{* *}\end{array}$ & $\begin{array}{l}-4.208 \\
(0.126)^{* *}\end{array}$ & $\begin{array}{l}-7.023 \\
(0.809)^{* *}\end{array}$ & $\begin{array}{l}-2.908 \\
(0.117)^{* *}\end{array}$ \\
\hline School FX & $\mathrm{NO}$ & $\mathrm{NO}$ & YES & YES \\
\hline
\end{tabular}

Table 8: Sample selection

Effect of moving into SH n'hood

Panel A: $20 \%$ vs $80 \%$ threshold: $\quad 0.400$

(1.231)

Panel B: Excluding y9-10 movers: $\quad-0.532$

(0.857)

Panel C: Only first cobort: $\quad-0.392$

(1.059)

Panel D: Only movers: $\quad-0.013$

(1.063)

Notes: All regressions include Output Area

(neighborhood) fixed effects, like Table 4 (column 4).

Standard errors in brackets. 
Table 9: Expanding the treatment period, years 6-9 and years 9-11 movers

\begin{tabular}{llllc}
\hline \hline & $(1)$ & $(2)$ & $(3)$ & $(4)$ \\
Move into SH neighborhood before KS3, between & -0.990 & 0.883 & 0.864 & 0.083 \\
years 6 and 9. & $(1.348)$ & $(0.825)$ & $(0.783)$ & $(0.992)$ \\
Move into SH neighborhood before or after KS3, & -12.767 & -3.596 & -2.344 & -0.177 \\
between years 6 and 11 & $(1.145)^{* *}$ & $(0.704)^{* *}$ & $(0.669)^{* *}$ & $(0.861)$ \\
Control for moving into social housing & Yes & Yes & Yes & Yes \\
Controls for effects of moving & Yes & Yes & Yes & Yes \\
Ethnicity-controls & No & Yes & Yes & No \\
School fixed effects & No & No & Yes & No \\
Output Area fixed effects (after move) & No & No & & No \\
\hline \hline
\end{tabular}

Notes: Here we compare KS3 scores for pupils who move into social housing neighborhoods during three years prior to taking the KS3 compared to pupils who move during the two years afterwards. Neighborhoods classified as Social housing if at least 80 per cent of residents in social rented sector. Movers only move once. Only pupils who always lived in Local Authority with more than $5 \%$ of population on Social Housing waiting list. 280k observations (based on only one cohort), 2,419 schools.

FIGURE 2: THE ENGLISH SCHOOL SYSTEM AND IDENTIFICATION

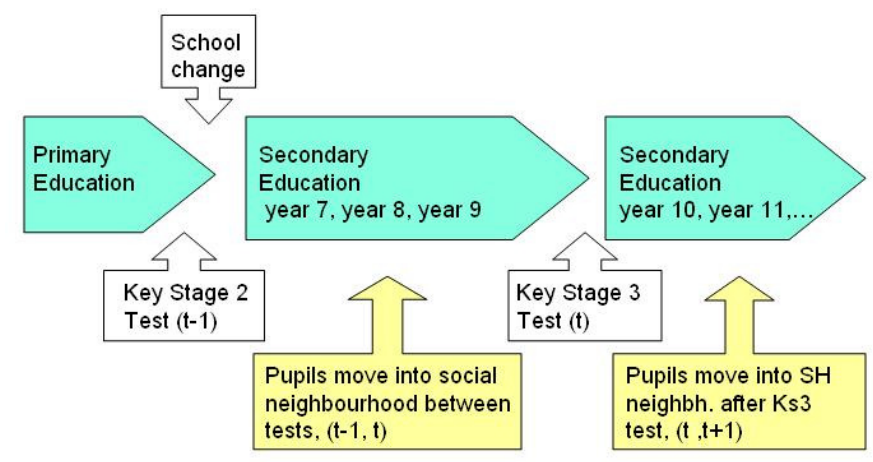


FIGURE 3: BALANCING OF PUPILS WHO MOVE INTO SH NEIGHBORHOODS PANEL A: TEST RESUlTS, GENDER, FSME (INCOME)

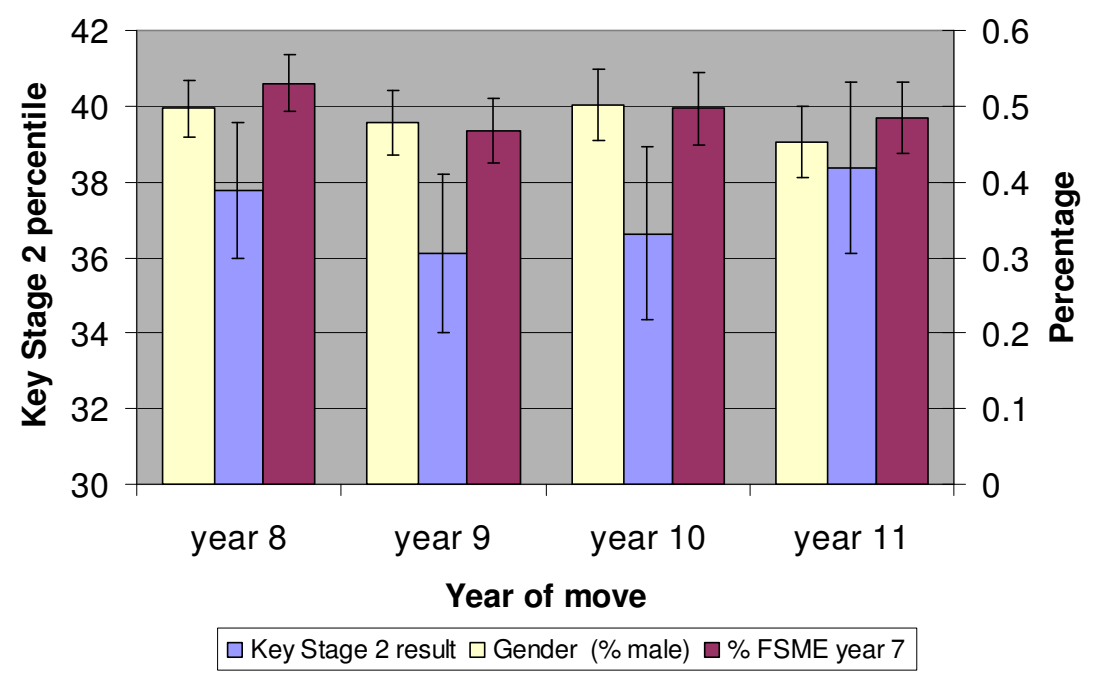

PANEL B: CHANGE IN NEIGHBORHOOD QUALITY FOR SH-MOVERS

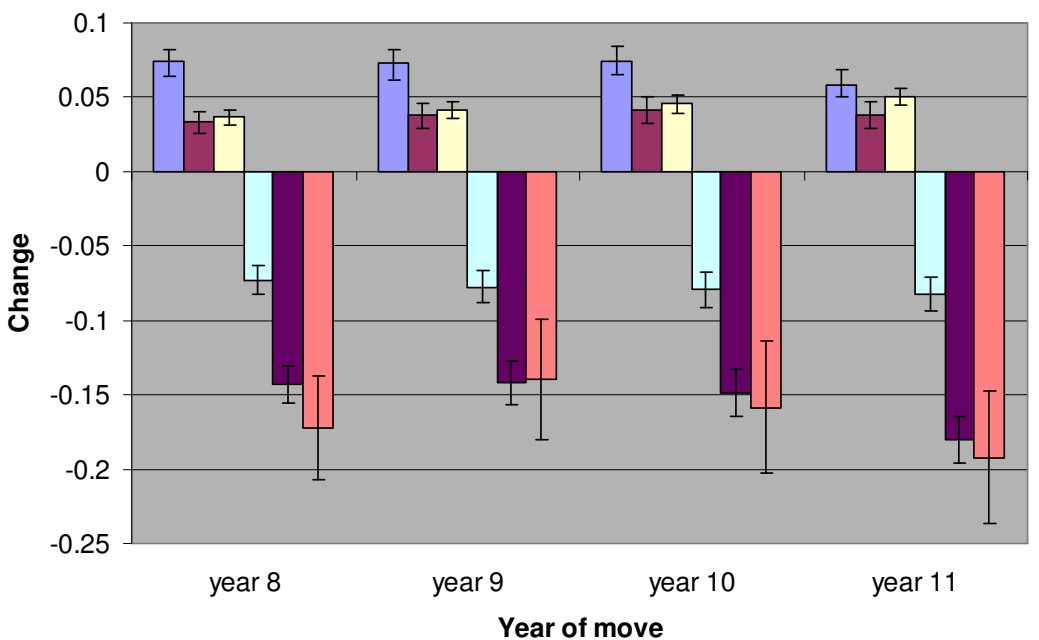

$\square \%$ Lone parent with dep. child $\square$ Unemployment rate

$\square$ Overcrowding index

$\square$ Access to car $\square \%$ Level 4+ qualification $\square$ Price Index 
FIGURE 4:

CHANGING THE THRESHOLD DEFINITION OF SOCIAL HOUSING NEIGHBORHOODS

Panel A: traditional vs DID

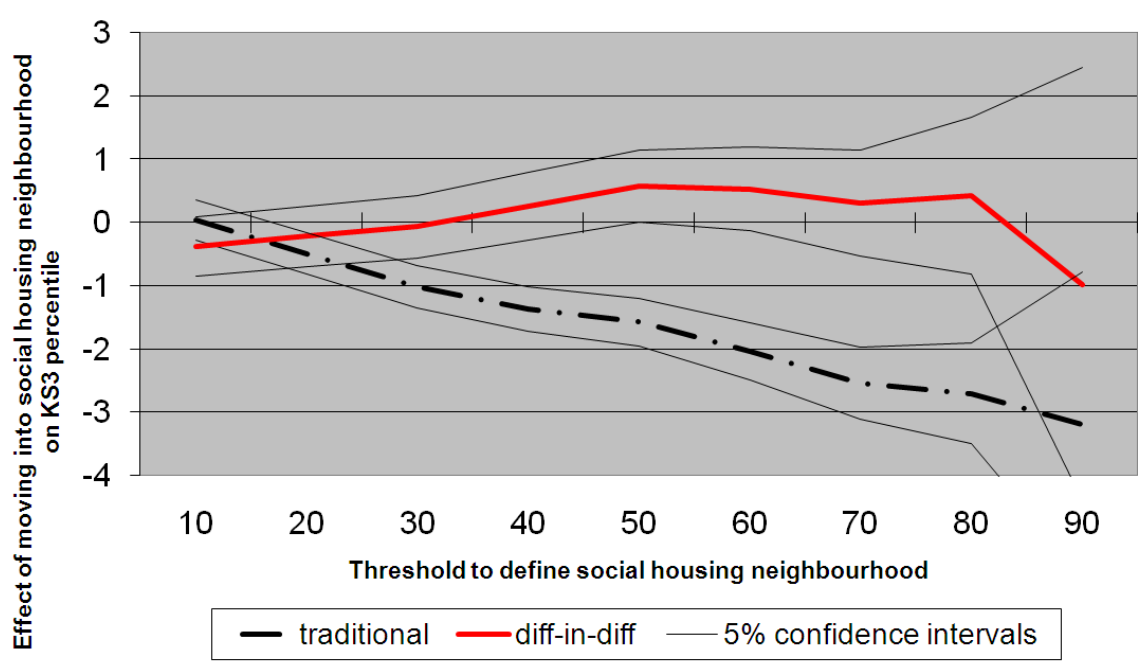

Panel B: with school fixed effects

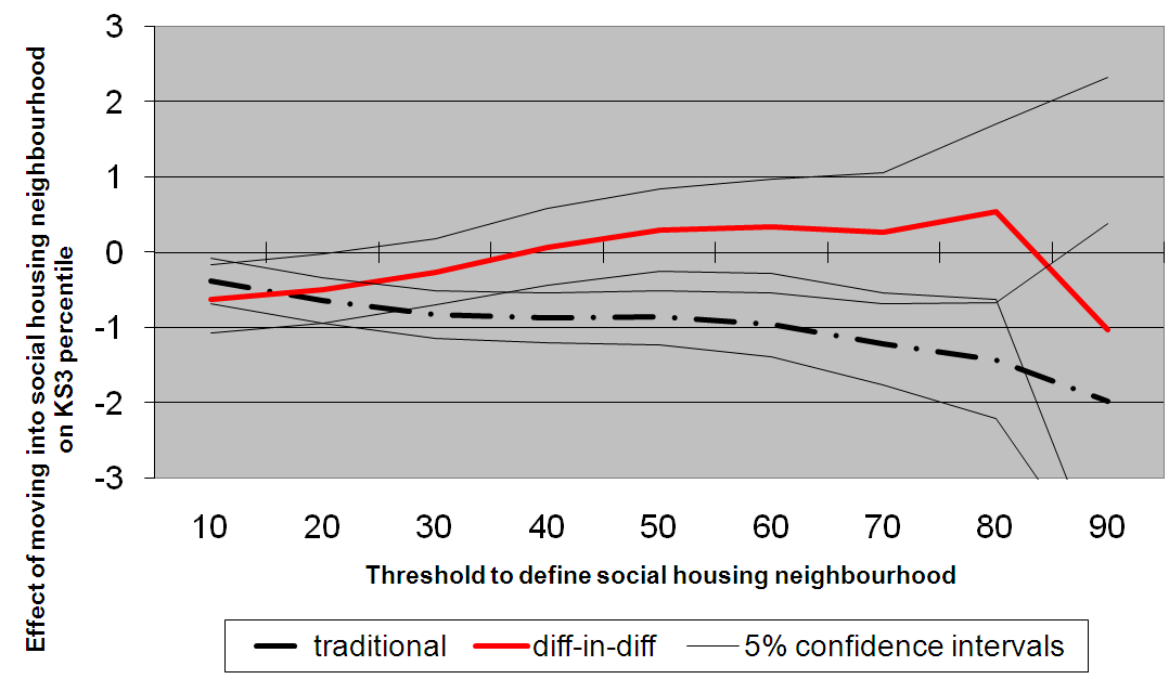

